\title{
Shared understanding of color among sighted and blind adults
} \section{0} 1

2 Authors: Judy Sein Kim ${ }^{1,2 *}$, Brianna Aheimer ${ }^{1}$, Verónica Montané Manrara ${ }^{1}$, Marina Bedny

Affiliations: ${ }^{1}$ Department of Psychological and Brain Sciences, Johns Hopkins University

(4)

${ }^{2}$ Department of Psychology, Yale University

${ }^{*}$ Correspondence to: judy.kim@yale.edu

\section{Classification: Social sciences, Psychological and Brain Sciences}

Keywords: color, concepts, intuitive theories, blindness, language 
Abstract

27 Empiricist philosophers such as Locke famously argued that people born blind could only acquire shallow, fragmented facts about color. Contrary to this intuition, we report that blind and sighted people share an in-depth understanding of color, despite disagreeing about arbitrary color facts. Relative to the sighted, blind individuals are less likely to generate 'yellow' for banana and 'red' for stop-sign. However, blind and sighted adults are equally likely to infer that two bananas (natural kinds) and two stop-signs (artifacts with functional colors) are more likely to have the same color than two cars (artifacts with non-functional colors), make similar inferences about novel objects' colors, and provide similar causal explanations. We argue that people develop intuitive and inferentially rich "theories" of color regardless of visual experience. knowledge of verbal facts. Significance Statement

39 We learn in a variety of ways: through direct sensory experience, by talking with others, and by thinking. Disentangling how these sources contribute to what we know is challenging. A wedge into this puzzle was suggested by empiricist philosophers, who hypothesized that people born prediction, we find that congenitally blind and sighted individuals share in-depth understanding of object color. Blind and sighted people share similar intuitions about which objects will have consistent colors, make similar predictions for novel objects, and give similar explanations. Living among people who talk about color is sufficient for color understanding, highlighting the efficiency of linguistic communication as a source of knowledge. 


\section{Introduction}

What and how do we learn from others, and what must we see for ourselves? A common intuition is that sensory phenomena have to be experienced directly to be fully grasped. Locke and Hume argued that an understanding of color was inaccessible to people born blind $(1,2)$. More recently, Frank Jackson suggested that Mary, a fictional color scientist living in a black and white room, would miss out on essential elements of color understanding that could only be gained through first-person experience $(2,4$, see also 5). Many contemporary theories of cognition, including embodiment theories, link knowledge of sensory phenomena to first-person experience. According to such views, visual experience is central to concepts like 'red' (6-12). Once created, the original sensory trace is activated by language and thinking. When one speaker says to another, "This car is red," mutual understanding makes use of a sensory common ground (i.e., prior visual experiences of red). Consistent with this idea, hearing color words activates brain regions involved in color perception (e.g., 13-15). Such views propose that people with different sensory experiences have different conceptual representations of sensory phenomena (e.g., each person's concept of red reflects the specific reds they have seen) $(11,7,14)$. Exactly what aspects of sensory knowledge come from sensory experience remains an open question.

In domains other than sensory phenomena, we gain much of our knowledge from other people through cultural transmission rather than from direct sensory experience (e.g., 16,17). Humans are highly adept at sharing knowledge within a society and across generations (18-22). Part of what makes cultural transmission so effective is language, a uniquely human and remarkably efficient communication system. Religious beliefs, internal contents of people's minds and social categories (e.g., gender) are among the many things we learn from others through language (e.g., 23-27). Here we ask what kind of understanding of sensory phenomena is transmitted via language by comparing knowledge of color among people who are blind and sighted living in the same culture. 
As noted above, a longstanding view in philosophy and psychology is that color knowledge in blindness is fragmented and empty $(1,2,28,29)$. However, unlike Mary the lone color scientist living in a black and white room, people born blind engage in ordinary linguistic communication with sighted people who experience color. What does such communication convey? Landau \& Gleitman (1985) were the first to challenge the idea of deficient "visual" knowledge in blindness, by showing that a congenitally blind 4year-old, Kelli, applied color words to concrete objects but not mental entities (e.g., ideas) and understood that color could only be perceived visually, unlike texture or size (30). Blind and sighted adults also share knowledge of similarities between colors (e.g., green and blue are similar but different from orange and red), although this knowledge is more variable among blind individuals (31-33). have identified substantial differences in blind and sighted people's color knowledge. Sighted people can report the colors of many objects (e.g., hippos are grey, and strawberries are red) and show high agreement; by contrast, agreement is lower among people who are blind and between sighted and blind people $(34,29)$. Moreover, agreement is lower among blind adults for color relative to other physical dimensions, such as shape, texture and size (34). Even when people who are blind agree with the sighted on the canonical color of an object (e.g., strawberries are red), blind individuals are less likely to use color as a dimension during semantic similarity judgments, leading to the suggestion that such knowledge is "merely stipulated" for blind but not sighted people (29). Converging evidence for the idea that language is limited in what it transmits about color comes from text corpus analyses, which are less successful at extracting color information from text, relative to other physical dimensions (e.g., shape) and abstract properties (e.g., taxonomy) (35-38). One interpretation of these results is that despite a rich vocabulary of color terms in English, everyday linguistic communication is limited in what it conveys about color.

However, these prior studies may underestimate the capacity of language to transmit color information. Like most studies of color knowledge in sighted people, these studies focused on knowledge of associative color facts such as that strawberries are red, rather than on inferentially rich, causal understanding of color (e.g., 39-43). Such color factoids might be least likely to be culturally transmitted since, for both sighted and blind people alike, they are inferentially shallow and disconnected from other 
100

101

102

103

104

105

106

107

108

109

110

111

112

113

114

115

116

117

118

119

120

121

122

123

124

125

126

127

things we know about objects. Little follows specifically from the fact that strawberries are red, as opposed to blue or purple.

In addition to such associative links between objects and their colors, even young children have causal-explanatory intuitions about color (44-45). These intuitions are a part of broader frameworks, often referred to as 'intuitive theories' about physical objects (e.g., 46-52). Children expect an object's relationship with color to differ depending on whether it is a natural kind (e.g., plant, animal, gem) or an artifact (e.g., machine, tool). In response to "Why is this object yellow?" children prefer explanations that appeal to biological mechanisms for natural kinds but human intentions for artifacts (45). In contrast to associative color facts, causal object-color links are both explanatory and can generate predictions about objects that have not previously been experienced. When asked, "Could something still be a Glick even if it was a different color?" 5-year-old children are more likely to say yes for an artifact than for an animal. By contrast, two instances of a natural kind (e.g., two strawberries) and two instances of an artifact (e.g., two cars) are judged equally like to have consistent shapes (44). Causal object-color relationships also differ among artifacts in ways that are related to human intentions, although this type of knowledge has not previously been tested. For artifacts such as stop signs and paper, color plays a functional role and is therefore consistent across tokens. Stop-signs are red for visibility and recognizability and paper is white to make markings visible. By contrast, for artifacts like cars and mugs, color is not related to function (e.g., transportation and holding liquid) and therefore can vary freely.

Is first person sensory experience instrumental to acquiring such causal-explanatory color knowledge? One possibility is that seeing stop-signs, paper, mugs, and cars is necessary for viewers to infer causal object-color relationships and to generalize such knowledge to novel instances, just like seeing animals appears to be highly useful to learning their specific colors (34). Here, we predicted instead that linguistic communication would be more effective at transmitting causal-explanatory color knowledge than associative color facts. Laboratory experiments suggest that children and adults are better at learning such causal-explanatory knowledge (53-55). Adults remember lists of features better if they can be related to each other and recall the same events and facts better if they are presented as coherent stories with causal structure (54-58). People naturally search for explanatory information by asking "why" (59-65). The process of explaining itself can boost memory for causal information: after being prompted to explain, children 
remember objects' features better when there is a link between it and how the object works, as opposed to when the relation is an arbitrary association $(66,53)$. These laboratory experiments suggest that causalexplanatory knowledge is learned more effectively than isolated facts. The case of color knowledge in blindness offers a test case of whether linguistic communication transmits causal-explanatory knowledge more effectively in naturalistic settings.

In the current study we probed sighted and congenitally blind people's associative and causalexplanatory knowledge of color in three experiments. Experiment 1 first queried associative memory for real objects' colors by asking participants to generate "a common color of X" (Figure 1). We next asked participants to judge how likely two instances of the same object are to have the same color, for natural kinds (e.g., two bananas) and artifacts (e.g., two cars). We reasoned that if people share intuitive theories about the relationship between color and object kind, blind and sighted people would make similar inferences about color consistency, even while disagreeing on associative facts (i.e., the particular colors of objects). We predicted that people would judge natural kinds and artifacts with function-relevant color (e.g., stop signs), but not artifacts with function-irrelevant color (e.g., cars), to have high color consistency across instances. For artifacts, to ask whether blind and sighted people make color consistency judgments by reasoning about the causal relationship between the object and its color, we additionally obtained judgments about the relevance of color to artifact function. We predicted that the color consistency ratings would correlate with functional relevance.

The ability to support generalization to novel instances is a key test of whether knowledge is inferentially-rich (e.g., 49,67). In Experiment 2, we thus asked participants to make inferences about color consistency for novel objects (natural kinds, artifacts with function-relevant color, and artifacts with functionirrelevant color) in an imaginary island scenario (Fig. 1). If knowledge about the origins and causes of color is shared, then blind and sighted participants might make systematic predictions for color consistency for novel objects on the basis of object category (e.g., creature, gem, or gadget, coin). Finally, in Experiment 3, we elicited open-ended explanations for why objects have their colors (e.g., "Why is a carrot orange?"). This allowed us to probe the specific nature of blind and sighted people's knowledge of the causal mechanisms that give rise to object colors. 


\begin{tabular}{|c|c|c|}
\hline & & Experiment 1: Real objects \\
\hline \multirow{3}{*}{ 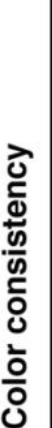 } & & $\begin{array}{l}\text { Q1: What is a common color of (a) } \\
\text { Q2: If you picked two } \\
\text { likely are they to be the same color? }\end{array}$ \\
\hline & $\begin{array}{l}\text { Natural } \\
\text { kinds }\end{array}$ & $\begin{array}{l}\text { All items: strawberry, banana, (pieces } \\
\text { of) broccoli, lemon, (pieces of) coal, } \\
\text { (peices of) snow, flamingo, elephant, } \\
\text { ruby, pearl }\end{array}$ \\
\hline & $\begin{array}{l}\text { Artifacts } \\
\text { (non- } \\
\text { functional) }\end{array}$ & $\begin{array}{l}\text { All items: (pairs of) pants, mug, book, } \\
\text { purse, lunch box, suitcase, couch, (pairs } \\
\text { of) shoes, vacuum, toilet }\end{array}$ \\
\hline
\end{tabular}

All items: "go" traffic light, fire truck, basketball, taxi cab, police uniform, dollar bill, tennis ball, chalkboard, street sign, crayon

\section{Experiment 2: Novel objects}

“Imagine that you're an explorer, and on your travels, you've discovered an island... the people on this island call themselves Zorkas..."

Example trial: You tag alongside a group of Zorka miners into a cave. There you notice a miner excavating a green gem that is spiky and the size of a hand. It appears to be vibrating in place. The miners tell you that this gem is called an Enly, and that Enlies are used as an energy source by the Zorka people. How likely is it that the next time you come across another Enly, it is also green?

Example trial: A Zorka woman invites you into her home. There, you notice a gadget that is floating around the house, spraying an odorless chemical. The gadget is triangular, yellow, and the size of a thumb. She says that this gadet is called a Kanpa, and that her Kanpa is rather old. How likely is it that the next time you come across another Kanpa, it is also yellow?

Example trial: You notice a Zorka teenager buying food with a square coin. She lets you examine it. It is very cold to the touch and red. She explains that this coin is called a Bewt, and that Bewt coins are the main currency used by the Zorka people. How likely is it that the next time you come across another Bewt, it is also red?

Q1: What is a common thing you can do with (a) ?

Q2: If you picked two people at random and asked them each to do something with a how likely are they to do the same thing?

Example trial: You come across a young Zorka woman who is ripping out a strange plant from the ground. The plant is fuzzy, red, and has jagged leaves. The leaves flop around with the wind. She says that this plant is called an Irve. She tells you that the she likes the way Irves smell. How likely is it that the next time you come across another Irve,

it is also being ripped out of the ground?

Example trial: You come across a Zorka person using a loud and bulky machine that is orange. Large rocks go in from one end and a gooey liquid comes out of the other. He explains that this machine is called an Olan. The Olan was invented by a Zorka person from his town. How likely is it that the next time you come across another Olan, it is also being used to make a gooey liquid?
All items: (piece of) wood, rock, mud, flower

All items: hole puncher, stapler, hammer drill, iron, toaster, coffee maker, bed, pencil, bathtub

Fig1. Experimental conditions and trials for color consistency inference. Participants were asked about color and usage consistency for real (Experiment 1) and novel (Experiment 2) objects. In both experiments, color trials asked about natural kinds, artifacts with non-functional colors, and artifacts with functional colors, while usage trials asked about natural kinds and artifacts. Different items were used in every trial. For Experiment 1, all items used are listed, and for Experiment 2, one sample trial (an Appendix with full list of trials can be found in Supplementary Materials).

\section{Results}

\section{Knowledge of specific object colors among sighted and blind participants}

Blind and sighted participants were asked to name a common color of 54 real objects (Experiment 1, 30; Experiment 3, 24, collapsed for the current analysis) (Figure 2A). For both sighted and blind groups, color naming agreement was higher for natural kinds (e.g. lemon) than 
169

170

171

172

173

174

175

176

177

178

for artifacts with non-functional colors (e.g., car), but similar to artifacts with functional colors (e.g., stop signs) (Figure 2B; Simpson's Diversity Index for sighted, NK: M=0.86, 95\% Cl [0.77, 0.95]; A-NFC: $M=0.49,95 \% \mathrm{Cl}[0.35,0.63]$; A-FC: $M=0.74,95 \% \mathrm{Cl}[0.61,0.87]$; blind NK: $M=0.5,95 \%$ $\mathrm{Cl}[0.38,0.62] ; \mathrm{A}-\mathrm{NFC}: \mathrm{M}=0.24,95 \% \mathrm{Cl}[0.2,0.28]$; A-FC: $\mathrm{M}=0.48,95 \% \mathrm{Cl}[0.36,0.6])$. Naming agreement was substantially higher for sighted compared to blind participants across all object types, and there was no group-by-object kind interaction (result of regression, effect of group: $\chi^{2}(1)=71.11, \mathrm{p}<0.001, \omega_{p}^{2}=0.57$; effect of object type: $\chi^{2}(2)=20, \mathrm{p}<0.001, \omega_{p}^{2}=0.25$; objecttype-by-group interaction: $\left.\chi^{2}(2)=1.49, \mathrm{p}=0.5\right)$.

A "What is a common color of
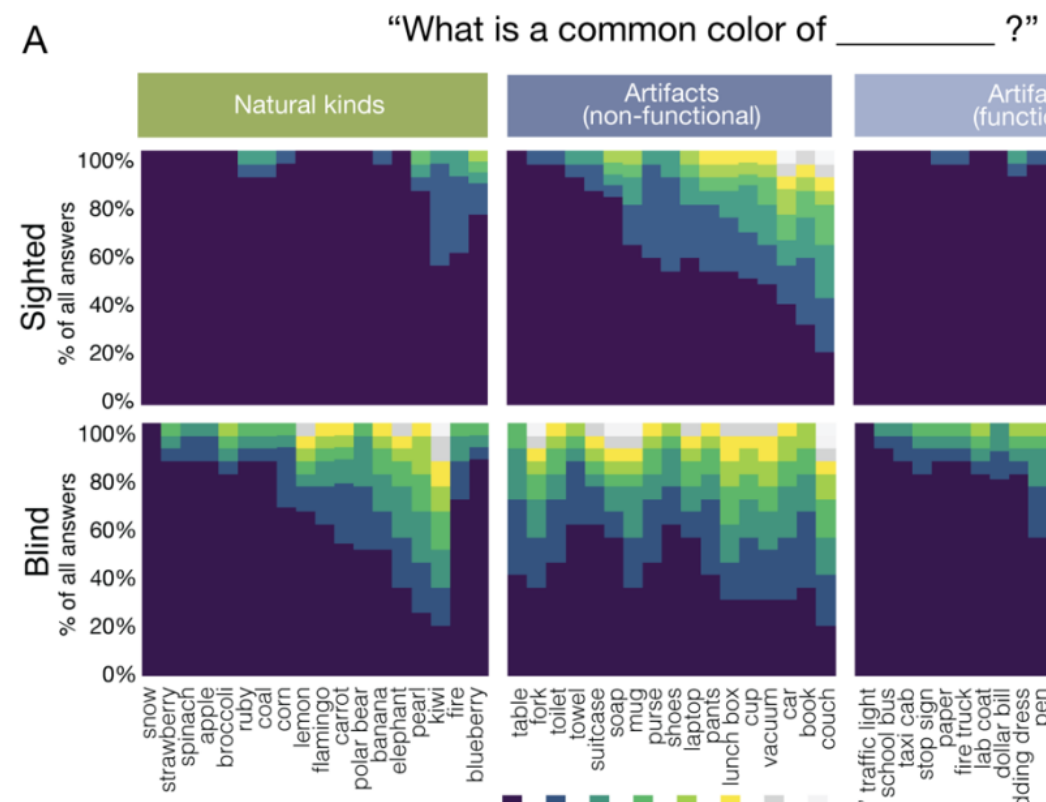

top1 top2 top3 top4 top5 top6 top7 top8

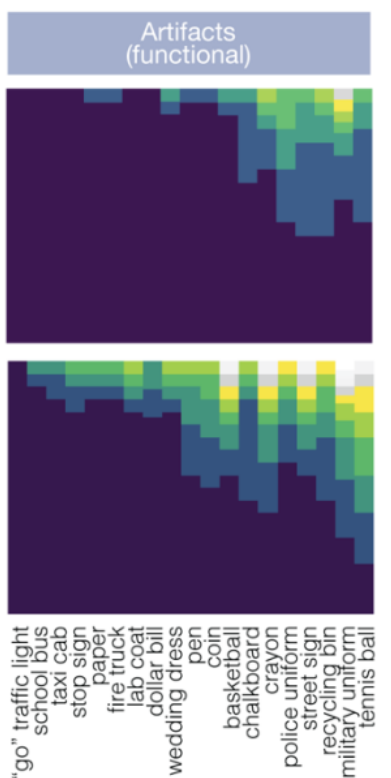

B

Color naming agreement

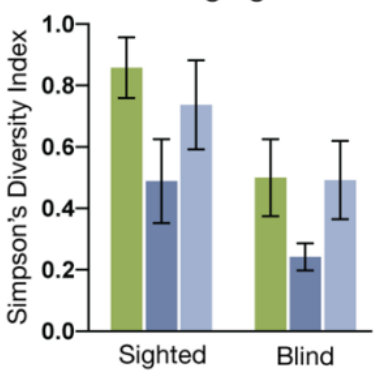

Fig 2. Object color naming agreement. Blind and sighted participants were asked to name common colors of real objects (Experiments 1 and 3). (A) Stacked bars show the frequency of the 8 most frequent colors provided for each object. Frequency for each unique color word is shown as a proportion of all words provided for an object. (B) Bar graph showing naming agreement (Simpson's Diversity Index calculated for individual objects). Mean $+/-95 \%$ confidence intervals (across objects). 


\section{Color consistency inferences in blind and sighted individuals: real objects}

Sighted and blind participants judged the likelihood that two objects (e.g. two lemons), randomly chosen from the same object category, would have the same color for 10 natural kinds (NK e.g. lemon), 10 artifacts with non-functional colors (A-NFC e.g. car) and 10 artifacts with functional colors (A-FC e.g. stop sign) (henceforth color consistency judgment). Participants rated consistency likelihood on a scale of 1 to 7 (1: not likely, 7: very likely). As a control, participants judged the likelihood that two people chosen at random would do the same thing with an object (e.g. a leaf vs. a car) (henceforth usage consistency judgment). Usage consistency was tested for 10 natural kinds (NK) and 10 artifacts.

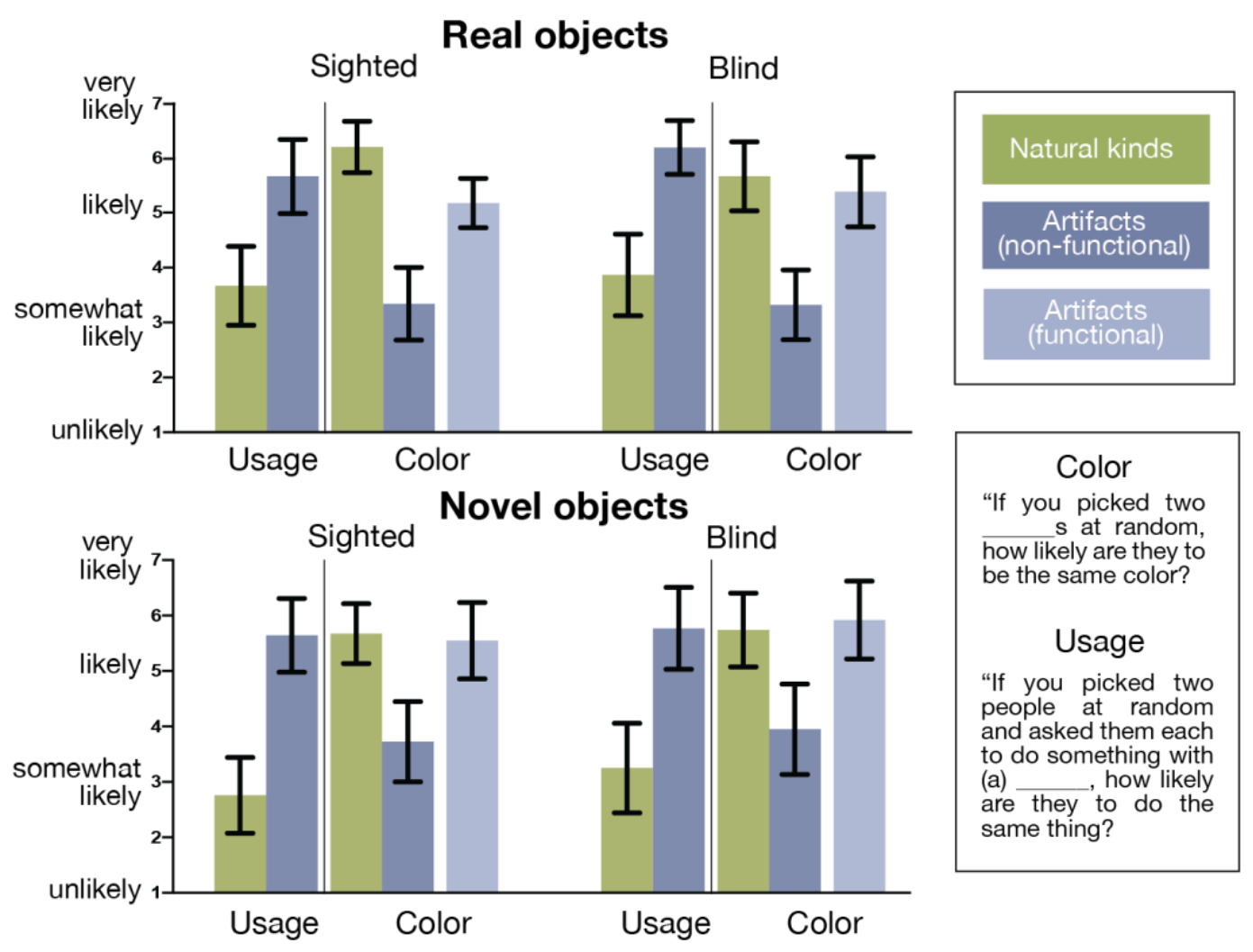

Fig 3. Inferences about color and usage consistency across instances of an object. Consistency judgments for real (Experiment 1) and novel (Experiment 2) objects. Bars are mean $+/-95 \%$ confidence intervals. 
Sighted participants judged natural kinds (e.g. lemons) to have lower usage consistency but higher color consistency, relative to artifacts (with non-functional colors, e.g. cars) (Fig. 3; sighted usage $\mathrm{NK}: \mathrm{M}=3.67,95 \% \mathrm{Cl}[2.96,4.38]$; usage $\mathrm{A}: \mathrm{M}=5.66,95 \% \mathrm{Cl}[4.99,6.33]$, Wilcoxon matched-pairs signed rank test for usage NK vs. A, two-tailed: $z=-3.82, p<0.001, r=0.88$; color NK: $M=6.2,95 \% \mathrm{Cl}[5.7,6.7]$, color A-NFC: $M=3.34 ; 95 \% \mathrm{Cl}[2.57,4.11]$; color NK vs. A-NFC, $z=3.78, p<0.001, r=0.87)$. Sighted participants' color consistency ratings for artifacts with functional colors (e.g., stop-signs) were higher than those for artifacts with non-functional colors and lower than those of natural kinds (color A-FC: $\mathrm{M}=5.17,95 \% \mathrm{Cl}[4.36,5.98]$, comparing A-FC vs. A-NFC: $z=3.8, p<0.001, r=0.87 ; A-F C$ vs. NK: $z=-3.66, p<0.001, r=0.84)$. For all artifacts, we obtained ratings of an object color's relevance to the its function from a separate group of sighted Amazon Mechanical Turk participants. These function relevance judgments for artifacts were positively correlated with sighted participants' color consistency judgments (Spearman's rank correlation: rho=0.61, $\mathrm{p}<0.001$; Fig. 4$)$.

The same effect of object type on color and usage consistency judgments was observed in the blind group. Blind participants again judged natural kinds to have lower usage consistency but higher color consistency, compared to artifacts (blind usage $\mathrm{NK}: \mathrm{M}=3.87,95 \% \mathrm{Cl}[3.16,4.58]$; A: $M=6.19,95 \% \mathrm{Cl}[5.69,6.69]$; Wilcoxon matched-pairs test for usage NK vs. $A: z=-3.92$, $\mathrm{p}<0.001, \mathrm{r}=0.88$; color NK: $\mathrm{M}=5.66,95 \% \mathrm{Cl}$ [4.99, 6.33]; A-NFC: $\mathrm{M}=3.32,95 \% \mathrm{Cl}[2.68,3.96]$; NK vs. A-NFC: $z=3.92, p<0.001, r=0.88)$. Artifacts with functional colors were judged to have higher color consistency than artifacts with non-functional colors, but lower than natural kinds (color A$F C: M=5.38,95 \%$ Cl $[4.59,6.17]$; comparing A-FC vs. A-NFC: $z=3.92, p<0.001, r=0.88 ; A-F C$ vs. NK: $z=-1.98, p=0.048, r=0.44)$. Blind participants' consistency judgments for artifacts were positively also correlated with MTurk participants' ratings of color's relevance to object function 226 


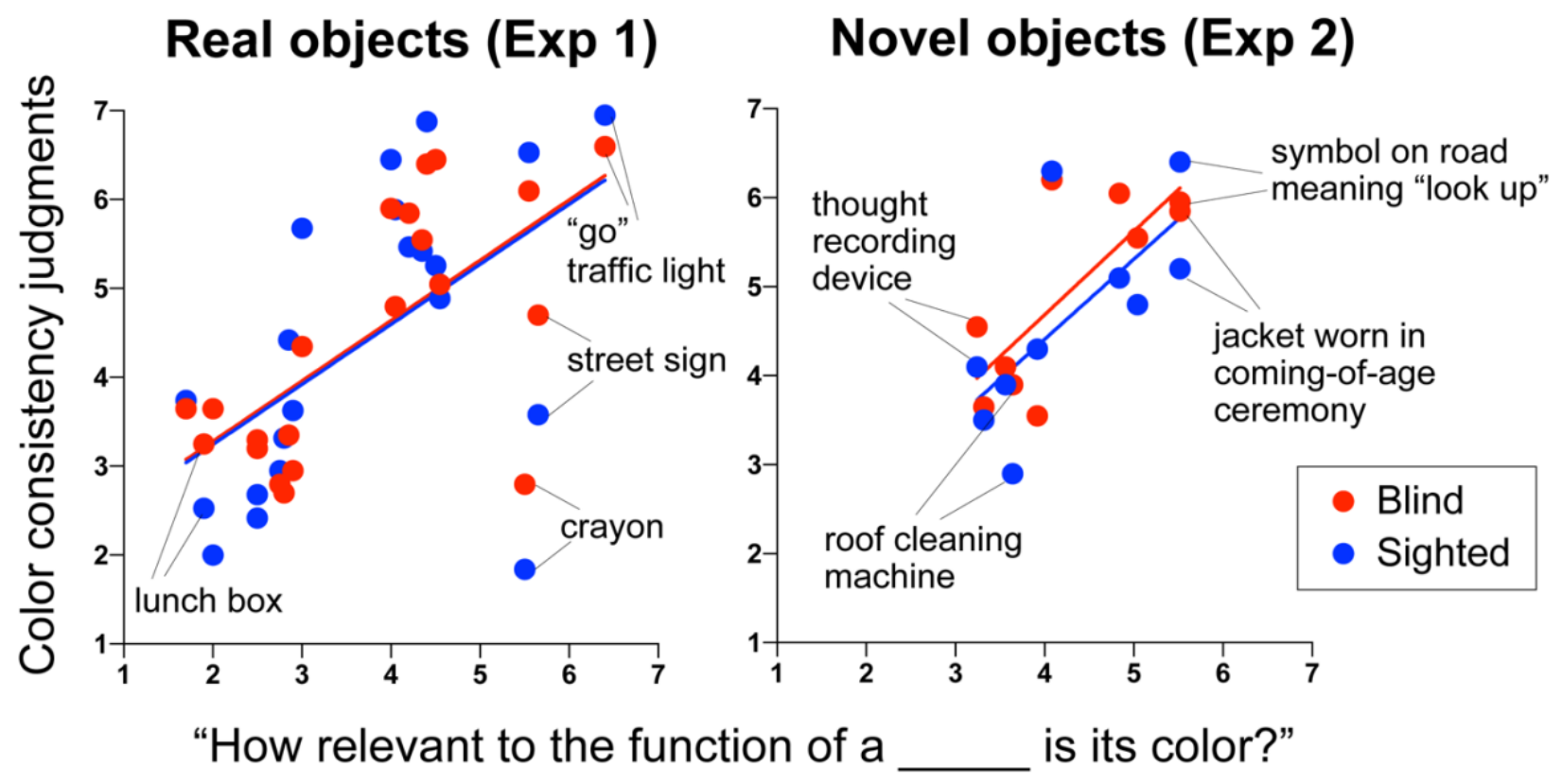

Fig 4. Relationship between functional relevance of color and consistency judgments for artifacts. Functional relevance judgments were obtained from separate groups of (sighted) participants on Mechanical Turk. Color consistency judgments are from Experiments 1 (real artifacts) and 2 (novel 231 artifacts). Red: blind and blue: sighted.

When groups were compared directly to each other, object kind and trial type did not interact with group (mixed ordinal logistic regression, group (blind vs. sighted) $x$ trial type (color vs. usage) $x$ object kind (NK vs. A-NFC), with sighted group, usage trial, and A-NFC treatment coded as baselines, no three-way interaction $(\beta=-0.24, \mathrm{SE}=0.38, \mathrm{z}=-0.63, \mathrm{p}=0.53)$. We also analyzed color judgments separately (group (blind vs. sighted) x object kind (NK vs. A-NFC vs. A-FC), with sighted and A-NFC as baseline). There was no significant interaction between group and object kind when comparing artifacts with functional color to artifacts with non-functional color

$240(\beta=0.45, \mathrm{SE}=0.27, \mathrm{z}=1.65, \mathrm{p}=0.1)$, although the interaction was significant when comparing 241 natural kinds to artifacts with non-functional color $(\beta=-1.02, \mathrm{SE}=0.27, \mathrm{z}=-3.78, \mathrm{p}<0.001)$. Although 242 both groups showed higher color-consistency judgments for natural kinds than artifacts with non- 
functional colors, the sighted, compared to blind group, the difference in ratings for natural kinds and artifacts with non-functional color is higher, and post-hoc tests show that this is driven by higher consistency ratings for natural kinds in the sighted (Wilcoxon test for sighted vs. blind NK: $z=2.48, p=0.013, r=0.4$; for artifacts FC: $z=1.15, p=0.3)$.

To compare blind and sighted individuals' reliance on artifact color-function relevance for judging color consistency, we further ran an ordinal regression model with consistency ratings as the DV and group and relevance ratings as predictors. Consistent with the high correlations reported above, there was a significant effect of relevance ratings $(\beta=1.16, S E=0.3, z=3.83$, $\mathrm{p}=0.0001)$ but no effect of group $(\beta=0.12, \mathrm{SE}=0.53, \mathrm{z}=0.23, \mathrm{p}=0.8)$ or a group by functionrelevance interaction $(\beta=-0.07, \mathrm{SE}=0.11, \mathrm{z}=-0.63, \mathrm{p}=0.5)$.

\section{Color consistency inferences in blind and sighted individuals: Novel objects}

For real familiar objects, blind and sighted individuals could make color consistency judgments based on knowledge of their actual color frequencies (e.g., learned from seeing or hearing that bananas are often yellow but that cars can be red, blue, black, etc.). Alternatively, or in addition, people may use a general understanding of the relationship between object kind (e.g., natural kind vs. artifact) and color (i.e., intuitive theories), to infer color consistency. Indeed, although on the whole color consistency judgments for real objects were similar across blind and sighted adults, people who are blind rated color consistency for natural kinds slightly lower than the sighted, possibly because of differences in associative object color-knowledge. To more directly test knowledge of general object-color relationships, we collected color consistency judgments for novel objects, for which neither blind nor sighted participants could have directly experienced their color. Participants were presented with "explorer on an island" scenario and judged the consistency of color and usage for novel natural kinds (e.g., gem, plant) (5 objects), novel artifacts with non-function-relevant colors (e.g. cleaning-gadget, speaking device) (5 
objects), and novel artifacts with function-relevant colors (e.g. coin, ceremonial clothing) (5 objects).

As with real objects, both groups judged artifacts to be more likely to have consistent usage than natural kinds (sighted usage NK: $\mathrm{M}=2.76,95 \% \mathrm{Cl}[2.12,3.4] ; \mathrm{A}: \mathrm{M}=5.64,95 \% \mathrm{Cl}$ $[5.02,6.26]$; Wilcoxon matched-pairs signed rank test for NK vs. A: $z=-3.82, p<0.001, r=0.88$; blind usage NK: $M=3.25,95 \% \mathrm{Cl}[2.49,4.01]$; $\mathrm{A}: \mathrm{M}=5.77,95 \% \mathrm{Cl}[5.08,6.46]$; NK vs. $\mathrm{A}: \mathrm{z}=-3.92$, $\mathrm{p}<0.001, \mathrm{r}=0.88)$. For color trials, consistency was again judged to be higher for natural kind s than for artifacts with non-functional color by both groups (sighted color NK: $\mathrm{M}=5.67,95 \% \mathrm{Cl}[5.17$, 6.17]; A-NFC: $M=3.73,95 \% \mathrm{Cl}[3.06,4.4]$; NK vs. A-NFC: $z=3.81, p<0.001, r=0.84$; blind color NK: $M=5.74,95 \%$ Cl $[5.12,6.26] ; A-N F C: M=3.95,95 \%$ Cl $[3.19,4.71]$; NK vs. A-NFC, $z=3.72$, $p<0.001, r=0.85)$. For both groups, artifacts with functional colors were judged as likely to have consistent colors as the natural kinds but more likely compared to artifacts with non-functional colors (for sighted color A-FC: $M=5.55,95 \% \mathrm{Cl}[4.74,6.36]$; NK vs. A-FC: $z=-0.65, p=0.52$; ANFC vs. A-FC: $z=3.78, p<0.001, r=0.87$; for blind color $A-F C: M=5.92,95 \% \mathrm{Cl}[5.26,6.58]$; NK vs. $A-F C: z=1.03, p=0.3 ; A-N F C$ vs. $A-F C: z=3.9, p<0.001, r=0.87)$.

The interaction between group, question type, and object kind was non-significant (mixed ordinal logistic regression, three-way interaction: $\beta=-0.15, \mathrm{SE}=0.93, \mathrm{z}=-0.16, \mathrm{p}=0.9)$. The groupby-object kind interaction for color trials only were also not significant (for NK vs. A-NFC: $\beta=-0.07$, $\mathrm{SE}=0.36, \mathrm{z}=-0.18, \mathrm{p}=0.9$, for $\mathrm{A}-\mathrm{FC}$ vs. A-NFC: $\beta=0.52, \mathrm{SE}=0.39, \mathrm{z}=1.39, \mathrm{p}=0.2)$.

For novel artifacts, both blind and sighted groups' consistency ratings were again positively correlated with function relevance ratings obtained from a separate group of sighted participants on Mechanical Turk (rho=0.73, $p=0.03$; for blind group: rho=0.57, $p=0.1$; Fig. 4). As with real objects, when consistency judgments were compared in one model with group and function relevance judgments as predictors, there was a significant effect of relevance ratings $(\beta=1.41, \mathrm{SE}=0.49, \mathrm{z}=2.87, \mathrm{p}=0.004)$ but no effect of group $(\beta=1.22, \mathrm{SE}=1.13, \mathrm{z}=1.07, \mathrm{p}=0.3)$ or a group by function-relevance interaction $(\beta=-0.43, \mathrm{SE}=0.26, \mathrm{z}=-1.65, \mathrm{p}=0.1)$. 


\section{Blind and sighted people's causal explanations of object color (Experiment 3)}

In Experiment 3, blind and sighted participants were asked to explain why each object has its particular color. The explanations were coded according to what type of information they appealed to: process, depends on..., just is that way, material, social, maker of the object, visibility and cultural convention (see Supplementary Materials for coding details). Both blind and sighted participants provided rich and coherent explanations of the cause of object color (Figure 4). Both groups tended to provide different explanations for natural kinds, artifacts with non-functional colors, and artifacts with functional colors. For natural kinds, both groups most often said "it just is that way" (sighted: $33 \%$, blind: $36 \%$ ) or appealed to a process that give the object its color (sighted: $32 \%$, blind: $31 \%$ ). For example, participants often described how the process of photosynthesis makes plants green. By contrast for artifacts with non-functional colors (e.g. cars) both blind and sighted participants appealed to people's social and esthetic preferences (sighted: $64 \%$, blind: $44 \%$ ), and referred to the material of which the object was made (sighted: $18 \%$, blind: $13 \%)$. For example, people frequently stated "personal preference" as a cause for cars, and for cup, mentioned that they could be different colors depending on whether they are made of plastic, porcelain, or metal. For artifacts with functional colors, participants most often appealed to cultural convention (sighted: 57\%, blind: $51 \%$ ) and visibility (sighted: $24 \%$, blind: $23 \%$ ). For example, for school bus, participants frequently mentioned tradition and history, and for stop sign, that the color makes it easy to see.

We examined how similar explanations were across groups by computing Spearman's correlation across groups within object kind. The frequencies of explanations by type were highly correlated across groups for all three kinds of objects (natural kind: rho=0.99, $p<0.001$; artifacts with non-functional color: rho $=0.72, \mathrm{p}=0.03$; artifacts with functional color: $r h o=0.97$, 319 (within sighted group: natural vs. $A-N F C$ : $r h o=-0.31, p=0.4$; natural vs. A-FC: rho=-0.27, $p=0.5$; 
320 A-NFC vs. A-FC: rho=0.78, $p=0.01$; within blind group: natural vs. A-NFC: rho=-0.02, $p=1$;

321 natural vs. A-FC: rho=-0.37, $p=0.3 ; A-N F C$ vs. $A-F C: r h o=0.28, p=0.5)$.

"Why is a that color?"

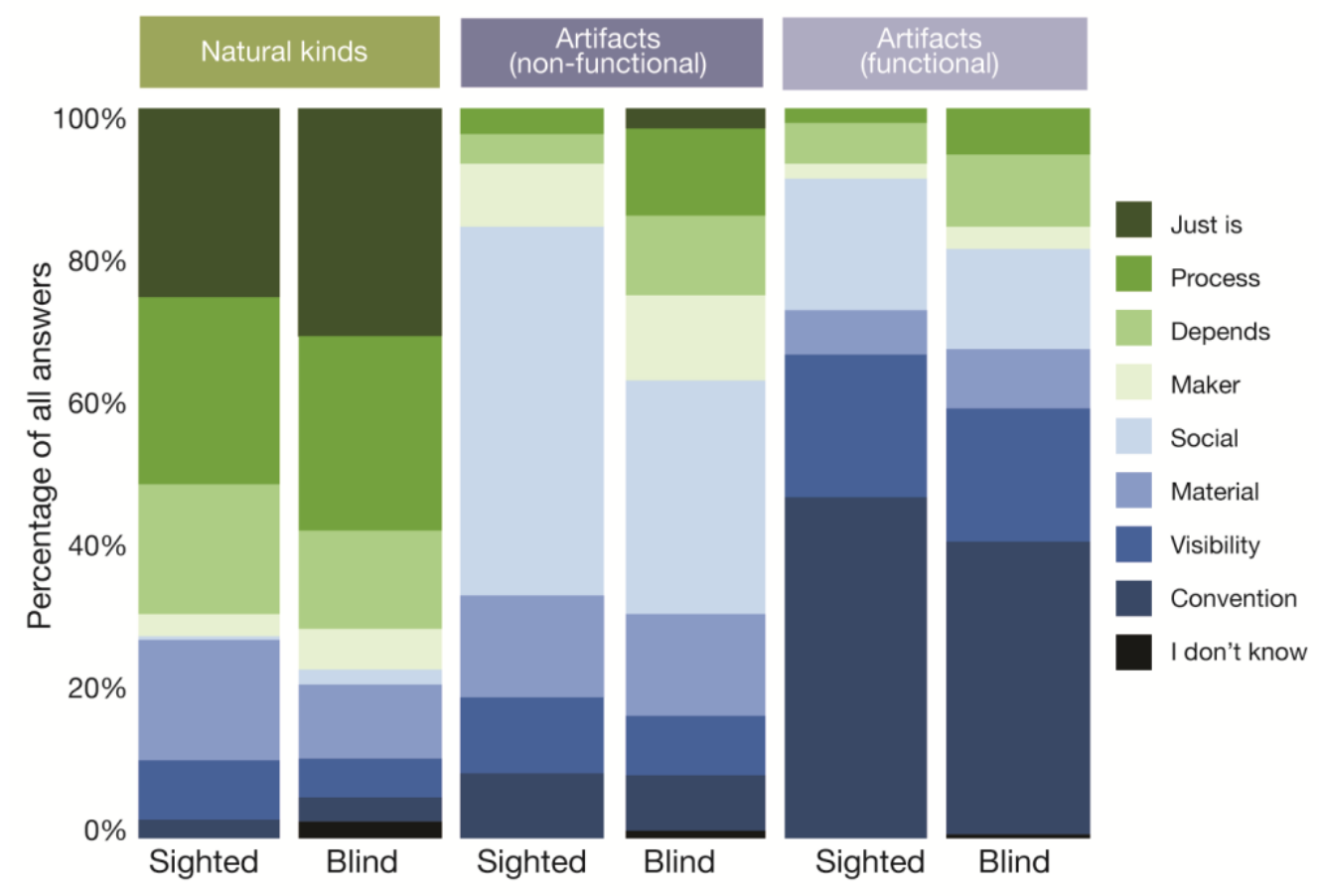

323 Fig 4. Explanations about object color. Explanation types were coded by 5 different coders who were

324 blind to group and object. Stacked bar shows the frequency of each explanation type as a proportion of all 325 explanations provided for an object (within object type) across participants (within a group). A detailed key 326 of explanation types can be found in Supplementary Materials. 
A straightforward idea is that we acquire color knowledge through seeing. Consistent with

330 this intuition, we find that people who have never seen are less likely to agree with each other 331 and with sighted people about associative color facts: although $100 \%$ of blind participants 332 generate the label 'white' for snow, only $50 \%$ say 'yellow' for bananas (compared to $100 \%$ and $95 \%$ of sighted people) (see also 34,29 ). This observation suggests that direct visual access is more effective than linguistic communication at transmitting object-color associations.

By contrast, we find that causal and inferentially rich color knowledge is shared among blind and sighted individuals_-blind and sighted participants alike judge that two instances of a natural kind (e.g., two bananas or two gems) are more likely to have the same color than two instances of an artifact (e.g., two cars or two mugs). Blind and sighted people also provide similar explanations of why real objects have the colors that they do, and these explanations vary systematically across natural kinds and artifacts. For natural kinds, both blind and sighted appeal to an objects' intrinsic nature (e.g., "that's just how it is", "that's nature") or describe processes such as photosynthesis, growth, or evolution. For artifacts, participants consistently cite individuals' or groups of people's needs and intentions (e.g., culture, aesthetic preference, visibility). Blind individuals produce coherent explanations for object color even when they do not agree with the sighted about the typical color of that particular object type. For example, while both groups' explanations for the color of polar bears mention their arctic habitat, almost all sighted participants explain that their white fur allows camouflage in the snow while some blind participants explain that polar bears are black to absorb heat in the cold. (Polar bears indeed have black skin underneath their white fur, and these features are thought to have evolved for camouflage and heat absorption respectively) (68). Such cases provide an illustration of causal understanding of color that is independent of knowing object-color associations. 
Blind and sighted people's intuitions about the relationship between kind and color go beyond the natural kind/artifact distinction (69). Among artifacts, people give higher color consistency ratings for those that have functionally relevant colors (e.g., paper, stop-signs) as opposed to those that do not (e.g., cars, mugs). Ratings of how important color is to an artifact's function are highly correlated with blind and sighted participants' ratings of color consistency. Explanations produced by sighted and blind adults also vary systematically by artifact type. For household and personal items such as mugs and cars, participants appeal to aesthetic preferences. For institution-related objects like police uniforms and dollar bills, participants cite social need for recognition. For stop signs, participants appeal to visibility (e.g., "red because red jumps out and warns people to stop"). Across artifacts, sighted and blind alike appeal to a range of causes such as camouflage, recognizability, cultural convention, symbolism, history, and aesthetic preference.

Finally, sighted and blind people make similar color consistency inferences for novel objects with which neither group has visual or linguistic experience. For example, both blind and sighted participants judge that two instances of a novel gem (natural kind) would be more likely to have the same color than two instances of a novel household gadget (artifact). Blind and sighted people also make distinctions within novel artifacts, intuiting which are most likely to have functionally relevant and therefore consistent colors (e.g., coins, toxic waste containers). As with real objects, ratings of color's relevance to object function for novel artifacts predicted color consistency ratings. Neither blind nor sighted people have had the opportunity to learn the statistics of color consistency for these novel types, since they have only heard their color specified once during the experiment (e.g., a noise-emitting, oval-shaped orange toxic waste container called a Bollop that people regularly use). Systematic judgments for these objects depend on causally connecting their function with color as well as possibly analogizing to existing objects' causally-relevant dimensions (e.g., reasoning about the toxic waste container's color by thinking about the purpose of recycling bin colors). Together, this evidence suggests that people 
living in the same culture develop similar intuitive theories of color regardless of their visual experience, and use these theories to make inferences that go beyond the data.

The present work leaves several open questions about color knowledge of sighted and blind people. First, it is worth noting that the present results do not speak to the issue of phenomenology (i.e., what it is like to see color), a key piece of knowledge said to be missing for Mary the color scientists (4). Indeed, such phenomenological or qualia knowledge might be empirically intractable (e.g., 5). With regard to intuitive theories of color, although we find substantial shared knowledge among sighted and blind people, further work is needed to fully characterize this knowledge in both populations. The present results do not rule out the possibility of some differences in color inferences as a function of perceptual experience. Although the overall pattern of color consistency judgments was highly similar between sighted and blind people, we observed slightly higher color consistency judgments for natural kinds among sighted as compared to blind people. We may also have failed to detect other small differences due to the relatively small sample size of the current study. The present results clearly show, however, that if differences in intuitive theories of color do exist between people who are sighted and people who are blind, these differences are more subtle than the robust differences in associative color knowledge. Finally, the present results are not inconsistent with the possibility of other color knowledge, not studied here, that differs among sighted and blind people. Indeed, recent evidence suggests both neural similarities and differences between blind and sighted people's representations of color: while objects with similar colors show similar patterns of activity in the anterior temporal lobe of both blind and sighted individuals, color perception regions in visual cortex additionally encode color similarity in sighted individuals (70, see also 71-72). The full typology of color knowledge in sighted and blind people remains to be fully described. Importantly, the present results demonstrate that there is much more to color knowledge than verbal facts and sensory (visual) representations. 
Within the domain of causal, intuitive-theoretic color knowledge, much remains to be uncovered in both sighted and blind people. We hypothesize that, like in other domains, the intuitive theories of color of both blind and sighted individuals will differ in substantial ways from formal scientific color theories $(73,69)$. Participants' explanations of object colors did sometimes cite scientifically studied processes (e.g., photosynthesis), but more commonly consisted of informal justifications lacking mechanistic detail (e.g., "that's just how it grows", "it's nature", "God made it that way", "manufacturer decided to paint it that way", "the material it's made of"). When more specific causes and processes are mentioned, they are often social and historical, and unlikely to be taught through formal education (e.g., both blind and sighted participants mentioned personality of the owner for cars and "the patriarchy" for the color of wedding dresses). During development, sighted children's beliefs about color depart systematically from scientific knowledge. Children mistakenly believe that an object will continue to have the same color even when the lighting source is changed, that objects emit their own shadows, and that a green object will have a green shadow (74-77). Children's explanations about such phenomena omit crucial components, such as the source and nature of light illuminating an object (74). Similar inconsistencies between scientific and intuitive theories have been observed in numerous other knowledge domains (e.g., physics: 78; biology: 79; psychology: 80). Even when educated adults and experts report strong confidence in their own understanding, their explanations for how things work are coarse and incomplete (81). Future work is needed to understand the ways in which intuitive theories of color among sighted and blind people share features with and depart from scientific color theories.

Importantly, the present evidence demonstrates that linguistic communication is highly adept at transmitting an understanding of sensory phenomena, including color. Previous studies with blind adults and text corpus analyses reported that object colors are less well transmitted by linguistic communication than other physical (e.g., shape, texture) and abstract dimensions (e.g., taxonomy) $(35,36,82)$. Proposed explanations for this observation include color not being 
accessible through modalities other than sight and/or being less talked about (34-36). Here we show that unlike associative color facts, those aspects of color knowledge that are causal and inferentially rich are transmitted with high fidelity by linguistic communication. These findings suggest that color knowledge per se is not less linguistically accessible. Instead, language preferentially transmits causal, inferentially rich information over associative facts. This hypothesis parsimoniously explains both the current findings and the previous observation that associative color facts are less likely to be transmitted than other physical dimensions, since previous work focused on those aspects of color knowledge that are less causally linked to objects than other aspects of physical appearance. For example, people who are blind were less likely to agree with sighted people on color, than on shape, texture and size of animals. Relative to color, texture, and shape are all more causally linked to an animals' taxonomic group and habitat. If we know that an animal lives in water, we can infer it is shaped like other sea-dwelling creatures, and if it is a bird, it is likely to have feathers (34). By contrast, both swans and polar bears are white, despite having no taxonomic or habitat relationship. Together, these data suggest that language preferentially transmits causally-relevant and inferentially rich appearance knowledge.

The present results also provide insight into why text-corpus analyses struggle to extract some kinds of perceptual information (e.g., color, 82, 37, 38). Although text corpus analyses do not build causal models or show preferential memory for causal material, we hypothesize that they are more likely to learn causally relevant perceptual features from text for related reasons: causally-relevant features are more attested in the linguistic signal and more correlated with other object properties. For example, text corpus analyses can guess that two animals have the same shape if they generally occur in similar linguistic contexts. By contrast, such guessing will not work for animal color. Evidence from people who are blind highlights the fact, the way people learn about appearance through language differs in important respects from the statistical tracking used by current text analysis algorithms. Unlike such algorithms, people incorporate linguistic information into causal intuitive theories through inference (see also 83, 84). The constructed 
theories enable people to make predictions about objects they have never encountered and to produce explanations $(67,85)$. This is also in part what enables humans to learn more about real object appearance from the linguistic signal: by filling in gaps in the data through inference.

Unlike most corpus-analysis algorithms, humans also make use of grammatical information (e.g., 30, 86). In the case of object color consistency, generics are one relevant type of grammatical construction. Hearing "this car is red," as opposed to "tomatoes are red" and "stop signs are red" could provide evidence about color consistency. Generic constructions are likely to be important since object-color cooccurrence in text alone does not faithfully reflect color consistency. Most objects are equally like to co-occur with canonical and non-canonical colors in text (36). For example, 'crow' co-occurs with 'black' and 'white' with similar frequencies, presumably because noting unusual colors is more pragmatically useful (87). Sighted children use generic language to infer that a property is pervasive to an object type, as opposed to specific to a particular instance of that object (e.g., 88-90). Likewise, people who are blind could use generics as a cue to color consistency. Generics could also facilitate learning specific object colors. Although people who are blind are less likely to agree with sighted people on specific animal colors than shapes, blind participants, but not text corpus analyses, are still most likely to generate the canonical color (Kim et al., 2019b). In sum, the richness of information humans glean from language about appearance implies use of linguistic evidence in sophisticated ways to transform intuitive theories through inference $(90,18,92)$.

The present results raise new questions concerning the role of language as opposed to sensory observation in the development of intuitive theories of color. One possibility is that for sighted people, language and vision convey redundant information, such that the same knowledge blind people acquire through language can be learned through vision by sighted people. If so, while blind and sighted people living in the same culture end up with similar theories by adulthood, there may be different trajectories in knowledge acquisition during development, with blind children showing later acquisition of the same information. Further, if language and 
vision are completely redundant, we would expect those with typical color experience but limited early access to language (e.g., deaf children born to parents who do not sign) to have theories equivalent to those of sighted and blind people reported here. Alternatively, it remains possible that language conveys unique information about color. Future work is needed to uncover precisely how blind and sighted people use language as a source of information when constructing intuitions about color. Studies of acquisition in blind children and work with populations with different language access would provide important insight into how, and with what information such intuitions are constructed.

In summary, we find that blind and sighted individuals alike possess theory-like, inferentially rich knowledge about the relationship between objects and their colors. These intuitive theories of color support consistent generalizations in the face of limited information (e.g., for novel objects), invoke deep causes (e.g., object function), support the generation of sophisticated explanations, apply to broad categories (e.g., all plants) as well as to specific instances (e.g., polar bears), and are specific to color. Interestingly, such structured and inferentially rich color knowledge appears to be more resilient to the lack of first-person sensory experience than knowledge of associative color facts. This observation directly contradicts the common intuition that blind people's knowledge of color consists of meaningless arbitrary facts. Language appears to support the updating of causal models much more robustly than it does the acquisition of arbitrary facts.

The case of color knowledge in blindness illustrates the capacity of testimony to transmit in-depth understanding of sensory phenomena. It also provides complementary support for the idea that language is a powerful source of information for intuitive theory construction. For many previously studied domains of knowledge, language-induced learning could in principle piggyback on pre-existing structured knowledge built through sensory observation. For example, learning that the earth is round might piggyback on learning roundness through vision and touch (93). Even in the case of mental phenomena, simulation of one's own feelings and thoughts has been 
offered as a source of "first-person" information about others' minds (94, 95). Analogously, a sighted person might construct a representation of a novel animal described as blue and large by referencing physical knowledge previously built up through sensory experience of color and size (34). In the case of color knowledge among blind individuals, there is no directly pertinent sensory information. Nevertheless, inferentially rich knowledge is constructed through inference from linguistic communication. The current findings also support the claim that language is especially adept for cultural transmission of causal intuitive theories (96-98). In this regard, the current findings are consistent with evidence form laboratory experiments showing that children and adults remember facts better when they are linked by causes than when they are merely statistically associated $(66,53)$. Evidence from color knowledge in blindness complements these findings by showing that language preferentially conveys inferentially rich, causal knowledge in naturalistic cultural transmission.

\section{Methods}

\section{Participants}

Twenty congenitally blind ( $14 \mathrm{~F} / 6 \mathrm{M}$, age: $\mathrm{M}=30.85, S D=10.59$, years of education: $M=15.4$, $S D=2.23)$ and nineteen sighted (14F/5M, age: $M=31.21, S D=11.21$, years of education $M=15.79$, $\mathrm{SD}=1.82$ ) participants took part in the study (participant table can be found in Supplemental Materials, Table S1). All blind participants reported no experience with color, shape, or motion, and had at most minimal light perception. All blind participants were tested at the 2018 National Federation of the Blind Convention in Orlando, Florida. Age- and education-matched sighted participants were then recruited and tested in person in-lab (in Baltimore, Maryland). Subtests of the Woodcock Johnson III Tests of Achievements (Word ID, Word Attack, Synonyms, Antonyms, and Analogies) were administered to sighted and blind participants, and anyone scoring below two SDs from their own group's mean was excluded from further analyses. This resulted in one 
sighted participant (participant 20) being excluded. The study consisted of three experiments administered to all participants within the same session. Experimental procedures were approved by the Johns Hopkins Homewood Institutional Review Board, and all participants provided informed consent.

\section{Experimental Procedures Overview}

Experiment 1 and 3 queried knowledge of and inferences about the colors of real objects (30 objects in Experiment 1, 24 in Experiment 3). In Experiment 2, participants made color inferences about 15 novel objects. Experiment 2 was always administered first to prevent the real object judgments from influencing inferences made about novel objects. Within each experiment, two different trial orders were used, one for half of the participants within each group. Experimenters read aloud instructions and trials, and participant answers were audio-recorded and later transcribed for scoring. The full list of stimuli and instructions can be found in the Appendix (Supplemental Materials).

\section{Experiment 1: Knowledge of Real Object Colors}

In each trial of Experiment 1, participants were asked two questions about an everyday object (Fig. 1). Three types of questions were asked: color consistency (30 objects), usage consistency (20 objects), and fillers (20 objects). Objects used for color trials were either natural (10 objects) or manmade (20 objects), and manmade artifacts could have function-relevant color (FC, 10 objects) or non-function-relevant color (NFC, 10 objects). Usage trials consisted of 10 natural kinds and 10 artifacts. On filler trials, participants were asked questions about non-color features (size, shape, and texture). Filler trials consisted of 5 natural kinds and 15 artifacts in order to balance the overall number of natural kind and manmade trials. The full list of items used in color and usage trials can be found in main Figure 1. 
On color trials, participants were first asked, "What is one common color of (a) [object name]?", followed by, "If you picked two [object name]s at random, how likely are they to be the same color? Rate on a scale of 1 to 7 (1: 'unlikely', 3: 'somewhat likely', 5: 'likely', 7: 'very likely')." For usage trials, the questions were, "What is one common thing you can do with (a/some) [object name]?" and, "If you picked two people at random and asked them each to do something with (a/some) [object name], how likely are they to do the same thing, on a scale of 1 to 7 ?" Usage trials served as a control condition to ensure blind and sighted participants showed equivalent performance and were willing to rate artifacts as having some consistent properties.

\section{Experiment 2: Color inferences about novel objects}

In Experiment 2, in order to elicit inferences about novel objects parallel to in Experiment 1, participants were first presented an "Explorer on an Island" scenario:

“Imagine that you're an explorer, and on your travels, you've discovered an island in a remote corner of the world... You learn that the people on this island call themselves Zorkas... The Zorka people appear to have a highly advanced culture. They have their own language, tools, machines, buildings, vehicles, foods, customs, and so on. The ecology on this island is also different from what we're used to: it has its own plant and animal life, unusual rocks, minerals, and so on. You're trying to learn about how things work on this island...."

Participants then heard 35 short vignettes, each of which described an encounter with a novel object (natural kind, artifacts with functional color, and artifacts with non-functional color; Fig. 1). In each trial, several appearance features were noted (e.g., "green gem that is spiky and the size of a hand"). The object was then named (e.g., "The miners tell you that this gem is called an Enly.").

As in Experiment 1, participants were next asked to rate the likelihood that another instance of the same object would have the same color (e.g., "How likely is it that the next time you come across another Enly, it is also green?). In usage trials, the question asked the likelihood 
that the novel object would be used in the same way if encountered at another time (e.g., "How likely is it that the next time you come across another Irve, it is also being ripped out of the ground?"). In addition, there were 10 filler trials (7 natural kind, 3 manmade objects), in which participants were asked about the likely repeat occurrence of a non-color feature (e.g., shape, texture, size).

Color trials consisted of 5 natural kinds (plant, algae, gem, liquid from a plant, fruit), 5 artifacts with function-relevant color (coin, road symbol, toxic waste container, ceremonial clothing, clear substance being used to build a wall), and 5 artifacts with function-irrelevant color (an odor-emitting gadget, roof cleaning machine, two devices with ambiguous functions).

Usage trials consisted of 5 natural kind (creature, boulder, stone, flower, plant) and 5 artifacts (machine that makes square holes, storage device, toy, machine that turns stones into goo, and one contraption with ambiguous function).

Filler trials contained 7 natural kind (fruit, two creatures, rock, two plants, gem) and 3 artifacts (game device, type of pool, one contraption with ambiguous function).

\section{Experiment 3: Explanations about the cause of object color}

For an additional list of 24 real objects (8 natural kind, 9 manmade with functional color, 7 function-irrelevant color), we asked participants to report their common colors (as in Experiment 1). Common color reports for these 24 objects are collapsed with those from Experiment 1 in main Figure 2. For these objects, we additionally asked why objects had the particular color (or colors) that the participant provided: "Why are [object name]s that/those color[s]?" Participants were instructed to provide whatever explanation felt right to them. Participants were also asked whether the object has different colored parts, and if an object's color varies across instances, to report the other colors. The answer to these questions were not analyzed for the present study.

\section{Quantifying color naming agreement for real objects}


612 (Experiment 1: 30 objects, "What is one common color of...?" and Experiment 3: 24 objects,

613 "What is the most common color of...?"). For each object, we quantified naming agreement by 614 using the Simpson's Diversity Index (SDI) $(99,34)$. For unique color words (1 to R) provided for 615 each object across all participants within a group (blind or sighted), a naming agreement score 616 was calculated according to the equation below. $\mathrm{N}$ is the total number of words used across 617 participants for each object, and $n$ is the number of times each unique word (1 to $R$ ) was 618 provided. The index ranges for 0 to 1 , where 0 indicates that the same color word was never used by two participants (i.e., low color naming agreement), and 1 suggests all participants provided the same color (i.e., high naming agreement).

$$
S D I=\frac{\sum_{i=1}^{R} n_{i}\left(n_{i}-1\right)}{N(N-1)}
$$

Although participants were instructed to provide one color, a few participants provided multiple colors (at most three, e.g., "red, white, and blue"). All of these colors were included in 624 the analysis. Further, a small proportion of participants said "I don't know" or provided words 625 that were not typical color terms (dark, light, beige, neon). These responses were treated the same as color terms (“I don't know” was counted as one word, coded “IDK”). Since SDIs were not normally distributed, they were log-transformed. To examine differences in color naming agreement across groups, we then performed linear mixed effects regression on logtransformed SDIs, using Imer in R (100), with objects as random effects.

\section{Color consistency inference analysis}

Consistency likelihood judgments were analyzed using ordinal logistic regression using

633 the ordinal (101) package in R. Participants and objects were always included as random 634 effects, and separate models were used in each analysis described (e.g., for real vs. novel 635 objects). 
We first compared group differences for natural kinds and artifacts with non-functional

637 color only, since artifacts with functional color are a special category. This also allowed us to 638 look at a group (blind vs. sighted) $\mathrm{x}$ object kind (natural vs. artifact) $\mathrm{x}$ trial type (color 639 vs. function) three-way interaction. Baselines were coded as sighted group, usage trial, and 640 artifact. We then compared across groups for color trials only, this time including all three kinds 641 of objects (natural, artifact with functional color, artifact with non-functional color), with sighted 642 group and artifact with non-functional color as the baseline.

\section{Correlation with functional relevance of color for artifacts}

We obtained ratings from Amazon Mechanical Turk for the functional relevance of color to artifacts separately for real $(n=20)$ and novel $(n=25)$ objects. Participants were asked "How important is the color of a [object] to its function?" and had to rate on a scale of 1 to 7 (not at all to very relevant). For novel objects, participants were provided with the same "explorer on an island" scenario as in the main experiment. Artifacts designated as 'artifacts with functional colors' were those that received an average rating of 4 or above, and artifacts 'non-functional colors' all had ratings below 4 (Table S2 and S3). We correlated the average functional relevance ratings for each object with the average color consistency judgments, for blind and sighted groups separately (Spearman correlation). To compare across groups, we used ordinal logistic regression with group and relevance judgments as fixed effects and participants and 655 items as random effects.

\section{Analysis of explanations}

Explanation types were decided by the experimenters based on examining all the explanations (while blind to group and object). We decided on 9 types of explanations: 'process', 'depends on', 'just is', 'material’, ‘social/aesthetic', 'maker', 'visibility', 'convention’, and ‘I don’t know'. A key of explanations can be found in Supplemental Materials (Table S3). 

explanation came from. Note, however, that in a small number of instances participants said the object's name in their explanations, and at other times, it was fairly easy to discern the

664 object from the explanation.

There was large variability in how many words participants used in their explanations (range $=1$ to 165 words, $M=13$ words). This meant that each explanation (i.e., what one participant said for one object) could contain multiple explanation types. For example, a participants' answer that the color of a wedding dress is due to "symbolism, or personal style", was coded as containing 'convention' (for symbolism) and 'social/aesthetic' (for personal style) explanations. However, the same word or phrase (e.g., "personal style") was never coded for more than one explanation type.

Some participants gave lengthier explanations than others, without necessarily providing additional information (e.g., often telling anecdotal stories to make a point). For wedding dress, for instance, another participant explained: "well, there's something about tradition, and white being associated with purity and virginity and all that, but beyond that it's just a matter of demand, if you want a baby barf green wedding dress that's your problem". This explanation was also coded with 'convention' and 'social/aesthetic'.

Coding was then filtered according to the criteria that at least three out of four coders have to agree. The first author (5th coder) made some additional changes, again keeping group and objects blind, and overruled tagging for $<5 \%$ explanations. After this process, the number of explanation types per explanation (again, a single explanation from one participant for one object) only ranged from 1-3 (mean=1.26).

We compared explanations across groups within each object kind. Within a group and kind (e.g., sighted group, natural kinds), we calculated how frequently participants (across all participants within group) used each of the 9 explanation types. The counts were then calculated as a percentage of all explanations (within group and object kind). We then computed 
Spearman's correlations over the percentages (for 9 types) across groups, as well as across object kinds within groups.

\section{References}

1. Locke, J. (1924). 1690. An essay concerning human understanding, 1.

2. Hume, D. (1938). An Abstract of a Treatise of Human Nature, 1740. CUP Archive.

3. Jackson, F. (1982). Epiphenomenal qualia. The Philosophical Quarterly (1950-), 32(127), 127-136.

4. Jackson, F. (1986). What Mary didn't know. The Journal of Philosophy, 83(5), 291-295.

5. Nagel, T. (1974). What is it like to be a bat?. The philosophical review, 83(4), 435-450.

6. Barsalou, L. W. (1999). Perceptual symbol systems. Behavioral and brain sciences, 22(4), 577-660.

7. Barsalou, L. W., Simmons, W. K., Barbey, A. K., \& Wilson, C. D. (2003). Grounding conceptual knowledge in modality-specific systems. Trends in cognitive sciences, 7(2), 84-91.

8. Prinz, J. J. (2005). The return of concept empiricism. In Handbook of categorization in cognitive science (pp. 679-695). Elsevier Science Ltd.

9. Gallese, V., \& Lakoff, G. (2005). The brain's concepts: The role of the sensory-motor system in conceptual knowledge. Cognitive neuropsychology, 22(3-4), 455-479.

10. Lakoff, G., \& Johnson, M. (2008). Metaphors we live by. University of Chicago press.

11. Yee, E., Jones, M. N., \& McRae, K. (2018). Semantic memory. Stevens' Handbook of Experimental Psychology and Cognitive Neuroscience, 3, 1-38. 
12. Ostarek, M., \& Bottini, R. (2021). Towards Strong Inference in Research on Embodiment-Possibilities and Limitations of Causal Paradigms. Journal of Cognition, 4(1).

13. Richter, T., \& Zwaan, R. A. (2009). Processing of color words activates color representations. Cognition, 111(3), 383-389.

14. Simmons, W. K., Ramjee, V., Beauchamp, M. S., McRae, K., Martin, A., \& Barsalou, L. W. (2007). A common neural substrate for perceiving and knowing about color. Neuropsychologia, 45(12), 2802-2810.

15. Hsu, N. S., Kraemer, D. J., Oliver, R. T., Schlichting, M. L., \& Thompson-Schill, S. L. (2011). Color, context, and cognitive style: Variations in color knowledge retrieval as a function of task and subject variables. Journal of Cognitive Neuroscience, 23(9), 25442557.

16. Cavalli-Sforza, L. L., Feldman, M. W., Chen, K. H., \& Dornbusch, S. M. (1982). Theory and observation in cultural transmission. Science, 218(4567), 19-27.

17. Boyd, R., Richerson, P. J., \& Henrich, J. (2011). The cultural niche: Why social learning is essential for human adaptation. Proceedings of the National Academy of Sciences, 108(Supplement 2), 10918-10925.

18. Csibra, G., \& Gergely, G. (2009). Natural pedagogy. Trends in cognitive sciences, 13(4), 148-153.

19. Tomasello, M. (2016). Cultural learning redux. Child development, 87(3), 643-653.

20. Hewlett, B. S., Fouts, H. N., Boyette, A. H., \& Hewlett, B. L. (2011). Social learning among Congo Basin hunter-gatherers. Philosophical Transactions of the Royal Society B: Biological Sciences, 366(1567), 1168-1178.

21. Gweon, H. (2020). The role of communication in acquisition, curation, and transmission of culture. Behavioral and Brain Sciences, 43. 
22. Pyers, J., \& de Villiers, P. A. (2013). Theory of mind in deaf children: Illuminating the relative roles of language and executive functioning in the development of social cognition. Understanding other minds: Perspectives from developmental social neuroscience, 345-363.

23. Harris, P. L., Koenig, M. A., Corriveau, K. H., \& Jaswal, V. K. (2018). Cognitive foundations of learning from testimony. Annual Review of Psychology, 69, 251-273.

24. Gelman, S. A., \& Roberts, S. O. (2017). How language shapes the cultural inheritance of categories. Proceedings of the National Academy of Sciences, 114(30), 7900-7907.

25. Schick, B., De Villiers, P., De Villiers, J., \& Hoffmeister, R. (2007). Language and theory of mind: A study of deaf children. Child development, 78(2), 376-396.

26. Pyers, J. E., \& Senghas, A. (2009). Language promotes false-belief understanding: Evidence from learners of a new sign language. Psychological science, 20(7), 805-812.

27. Rhodes, M., Leslie, S. J., \& Tworek, C. M. (2012). Cultural transmission of social essentialism. Proceedings of the National Academy of Sciences, 109(34), 13526-13531.

28. Cutsforth, T. D. (1932). The unreality of words to the blind. Journal of Visual Impairment \& Blindness, 25(5b), 86-89.

29. Connolly, A. C., Gleitman, L. R., \& Thompson-Schill, S. L. (2007). Effect of congenital blindness on the semantic representation of some everyday concepts. Proceedings of the National Academy of Sciences, 104(20), 8241-8246.

30. Gleitman, L., \& Landau, B. (1985). Language and experience: Evidence from the blind child.

31. Shepard, R. N., \& Cooper, L. A. (1992). Representation of colors in the blind, color-blind, and normally sighted. Psychological Science, 3(2), 97-104.

32. Marmor, G. S. (1978). Age at onset of blindness and the development of the semantics of color names. Journal of Experimental Child Psychology, 25(2), 267-278. 
33. Saysani, A., Corballis, M. C., \& Corballis, P. M. (2018). Colour envisioned: Concepts of colour in the blind and sighted. Visual Cognition, 26(5), 382-392.

34. Kim, J. S., Elli, G. V., \& Bedny, M. (2019a). Knowledge of animal appearance among sighted and blind adults. Proceedings of the National Academy of Sciences, 116(23), 11213-11222.

35. Lewis, M., Zettersten, M., \& Lupyan, G. (2019). Distributional semantics as a source of visual knowledge. Proceedings of the National Academy of Sciences, 116(39), 1923719238.

36. Ostarek, M., Van Paridon, J., \& Montero-Melis, G. (2019). Sighted people's language is not helpful for blind individuals' acquisition of typical animal colors. Proceedings of the National Academy of Sciences, 116(44), 21972-21973.

37. Bruni, E., Boleda, G., Baroni, M., \& Tran, N. K. (2012, July). Distributional semantics in technicolor. In Proceedings of the 50th Annual Meeting of the Association for Computational Linguistics (Volume 1: Long Papers) (pp. 136-145).

38. Grand, G., Blank, I. A., Pereira, F., \& Fedorenko, E. (2018). Semantic projection: recovering human knowledge of multiple, distinct object features from word embeddings. arXiv preprint arXiv:1802.01241.

39. Witzel, C., \& Gegenfurtner, K. R. (2020). Memory color.

40. Hansen, T., Olkkonen, M., Walter, S., \& Gegenfurtner, K. R. (2006). Memory modulates color appearance. Nature neuroscience, 9(11), 1367-1368.

41. Tanaka, J. W., \& Presnell, L. M. (1999). Color diagnosticity in object recognition. Perception \& Psychophysics, 61(6), 1140-1153.

42. Kimura, A., Wada, Y., Yang, J., Otsuka, Y., Dan, I., Masuda, T., ... \& Yamaguchi, M. K. (2010). Infants' recognition of objects using canonical color. Journal of Experimental Child Psychology, 105(3), 256-263. 
43. Rathore, R., Leggon, Z., Lessard, L., \& Schloss, K. B. (2019). Estimating Color-Concept Associations from Image Statistics. IEEE transactions on visualization and computer graphics, 26(1), 1226-1235.

44. Keil, F. C., Smith, W. C., Simons, D. J., \& Levin, D. T. (1998). Two dogmas of conceptual empiricism: Implications for hybrid models of the structure of knowledge. Cognition, 65(2-3), 103-135.

45. Springer, K., \& Keil, F. C. (1991). Early differentiation of causal mechanisms appropriate to biological and nonbiological kinds. Child development, 62(4), 767-781.

46. Keil, F. C. (1992). The origins of an autonomous biology. In Modularity and constraints in language and cognition: The Minnesota symposia on child psychology (Vol. 25, pp. 103137).

47. Gelman, S. A. (2003). The essential child: Origins of essentialism in everyday thought. Oxford University Press, USA.

48. Greif, M. L., Kemler Nelson, D. G., Keil, F. C., \& Gutierrez, F. (2006). What do children want to know about animals and artifacts? Domain-specific requests for information. Psychological Science, 17(6), 455-459.

49. Gelman, S. A. (1988). The development of induction within natural kind and artifact categories. Cognitive psychology, 20(1), 65-95.

50. Bloom, P. (1996). Intention, history, and artifact concepts. Cognition, 60(1), 1-29.

51. Prasada, S., \& Dillingham, E. M. (2006). Principled and statistical connections in common sense conception. Cognition, 99(1), 73-112.

52. Brandone, A. C., Cimpian, A., Leslie, S. J., \& Gelman, S. A. (2012). Do lions have manes? For children, generics are about kinds rather than quantities. Child development, 83(2), 423-433.

53. Walker, C. M., Lombrozo, T., Legare, C. H., \& Gopnik, A. (2014). Explaining prompts children to privilege inductively rich properties. Cognition, 133(2), 343-357. 
54. Murphy, G. L., \& Allopenna, P. D. (1994). The locus of knowledge effects in concept learning. Journal of experimental psychology: learning, memory, and cognition, 20(4), 904.

55. Frazier, B. N., Gelman, S. A., \& Wellman, H. M. (2016). Young children prefer and remember satisfying explanations. Journal of Cognition and Development, 17(5), 718736.

56. Thorndyke, P. W. (1977). Cognitive structures in comprehension and memory of narrative discourse. Cognitive psychology, 9(1), 77-110.

57. Kintsch, W., Mandel, T. S., \& Kozminsky, E. (1977). Summarizing scrambled stories. Memory \& Cognition, 5(5), 547-552.

58. Pennington, N., \& Hastie, R. (1993). Reasoning in explanation-based decision making. Cognition, 49(1-2), 123-163.

59. Lombrozo, T. (2011). The instrumental value of explanations. Philosophy Compass, 6(8), 539-551.

60. Lombrozo, T. (2016). Explanatory preferences shape learning and inference. Trends in Cognitive Sciences, 20(10), 748-759.

61. Lagnado, D. A., \& Gerstenberg, T. (2017). Causation in legal and moral reasoning. Oxford handbook of causal reasoning, 565-602.

62. Chi, M. T., Bassok, M., Lewis, M. W., Reimann, P., \& Glaser, R. (1989). Selfexplanations: How students study and use examples in learning to solve problems. Cognitive science, 13(2), 145-182.

63. Chi, M. T., Slotta, J. D., \& De Leeuw, N. (1994). From things to processes: A theory of conceptual change for learning science concepts. Learning and instruction, 4(1), 27-43.

64. Bonawitz, E. B., van Schijndel, T. J., Friel, D., \& Schulz, L. (2012). Children balance theories and evidence in exploration, explanation, and learning. Cognitive psychology, 64(4), 215-234. 
65. Legare, C. H. (2014). The contributions of explanation and exploration to children's scientific reasoning. Child Development Perspectives, 8(2), 101-106.

66. Legare, C. H., \& Lombrozo, T. (2014). Selective effects of explanation on learning during early childhood. Journal of experimental child psychology, 126, 198-212.

67. Gerstenberg, T., \& Tenenbaum, J. B. (2017). Intuitive theories. Oxford handbook of causal reasoning, 515-548.

68. Grojean, R. E., Sousa, J. A., \& Henry, M. C. (1980). Utilization of solar radiation by polar animals: an optical model for pelts. Applied Optics, 19(3), 339-346.

69. Keil, F. C., Greif, M. L., \& Kerner, R. S. (2007). A world apart: How concepts of the constructed world are different in representation and in development. Creations of the mind: Theories of artifacts and their reprefsentation, 231-245.

70. Wang, X., Men, W., Gao, J., Caramazza, A., \& Bi, Y. (2020). Two forms of knowledge representations in the human brain. Neuron, 107(2), 383-393.

71. Bottini, R., Ferraro, S., Nigri, A., Cuccarini, V., Bruzzone, M. G., \& Collignon, O. (2020). Brain regions involved in conceptual retrieval in sighted and blind people. Journal of cognitive neuroscience, 32(6), 1009-1025.

72. Striem-Amit, E., Wang, X., Bi, Y., \& Caramazza, A. (2018). Neural representation of visual concepts in people born blind. Nature communications, 9(1), 1-12.

73. Carey, S. (1988). Conceptual differences between children and adults. Mind and Language, 3(3), 167-181.

74. Feher, E., \& Meyer, K. R. (1992). Children's conceptions of color. Journal of research in Science Teaching, 29(5), 505-520.

75. Naranjo Correa, F. L., Martinez Borreguero, G., Perez Rodriguez, A. L., Suero Lopez, M. I., \& Pardo Fernandez, P. J. (2016). A new online tool to detect color misconceptions. Color Research \& Application, 41(3), 325-329. 
76. Anderson, C. W., \& Smith, E. L. (1986). Children's Conceptions of Light and Color: Understanding the Role of Unseen Rays. Research Series No. 166.

77. Cohen, J., \& Nichols, S. (2010). Colours, colour relationalism and the deliverances of introspection. Analysis, 70(2), 218-228.

78. McCloskey, M. (1983). Intuitive physics. Scientific american, 248(4), 122-131.

79. Ilnagaki, K., \& Hatano, G. (2006). Young children's conception of the biological world. Current Directions in Psychological Science, 15(4), 177-181.

80. Malle, B. F., Knobe, J. M., \& Nelson, S. E. (2007). Actor-observer asymmetries in explanations of behavior: New answers to an old question. Journal of Personality and Social Psychology, 93(4), 491.

81. Rozenblit, L., \& Keil, F. (2002). The misunderstood limits of folk science: An illusion of explanatory depth. Cognitive science, 26(5), 521-562.

82. Rubinstein, D., Levi, E., Schwartz, R., \& Rappoport, A. (2015, July). How well do distributional models capture different types of semantic knowledge?. In Proceedings of the 53rd Annual Meeting of the Association for Computational Linguistics and the 7th International Joint Conference on Natural Language Processing (Volume 2: Short Papers) (pp. 726-730).

83. Lake, B. M., \& Murphy, G. L. (2020). Word meaning in minds and machines. arXiv preprint arXiv:2008.01766.

84. Marcus, G. (2020). The next decade in Al: four steps towards robust artificial intelligence. arXiv preprint arXiv:2002.06177.

85. Lombrozo, T., \& Vasilyeva, N. (2017). Causal explanation. Oxford handbook of causal reasoning, 415-432. 
86. Tessler, M. H., Bridgers, S., \& Tenenbaum, J. B. (2020, January). How many observations is one generic worth?. In Proceedings of the Annual Conference of the Cognitive Science Society.

87. Bergey, C., Morris, B., \& Yurovsky, D. (2020). Children hear more about what is atypical than what is typical.

88. Cimpian, A., Brandone, A. C., \& Gelman, S. A. (2010). Generic statements require little evidence for acceptance but have powerful implications. Cognitive science, 34(8), 14521482.

89. Tessler, M. H., \& Goodman, N. D. (2019). The language of generalization. Psychological review, 126(3), 395.

90. Brandone, A. C., \& Gelman, S. A. (2009). Differences in preschoolers' and adults' use of generics about novel animals and artifacts: A window onto a conceptual divide. Cognition, 110(1), 1-22.

91. Kim, J. S., Elli, G. V., \& Bedny, M. (2019b). Reply to Ostarek et al.: Language, but not co-occurrence statistics, is useful for learning animal appearance. Proceedings of the National Academy of Sciences, 116(44), 21974-21975.

92. Shafto, P., Goodman, N. D., \& Frank, M. C. (2012). Learning from others: The consequences of psychological reasoning for human learning. Perspectives on Psychological Science, 7(4), 341-351. 32.

93. Vosniadou, S., \& Brewer, W. F. (1992). Mental models of the earth: A study of conceptual change in childhood. Cognitive psychology, 24(4), 535-585.

94. Gordon, R. M. (1986). Folk psychology as simulation. Mind \& language, 1 (2), 158-171.

95. Gallese, V., \& Goldman, A. (1998). Mirror neurons and the simulation theory of mindreading. Trends in cognitive sciences, 2(12), 493-501. 
96. Boyer, P. (1998). Cognitive tracks of cultural inheritance: How evolved intuitive ontology governs cultural transmission. American Anthropologist, 100(4), 876-889.

97. Pinker, S. (2003). Language as an adaptation to the cognitive niche. Studies in the Evolution of Language, 3, 16-37.

98. DeVore, I., \& Tooby, J. (1987). The reconstruction of hominid behavioral evolution through strategic modeling. The Evolution of Human Behavior: Primate Models, edited by WG Kinzey, 183-237.

99. Majid, A., Roberts, S. G., Cilissen, L., Emmorey, K., Nicodemus, B., O'grady, L., ... \& Shayan, S. (2018). Differential coding of perception in the world's languages. Proceedings of the National Academy of Sciences, 115(45), 11369-11376.

100.Bates D, Mächler M, Bolker B, Walker S (2015). "Fitting Linear Mixed-Effects Models Using Ime4." Journal of Statistical Software, 67(1).

101. Christensen RHB (2019). "ordinal—Regression Models for Ordinal Data ." R package version 2019.12-10. https://CRAN.R-project.org/package=ordinal.

Acknowledgments: We thank the National Federation of the Blind convention, the blind community, and all of our participants for making this research possible;

Funding: This work was supported by the National Institutes of Health (R01 EY027352 to M.B.) and the Johns Hopkins University Catalyst Grant (to M.B.); J.S.K was funded by the William Orr Dingwall Dissertation Fellowship;

Author contributions: J.S.K, B.A, V.M, and M.B. designed research; J.S.K, B.A, and V.M, performed research, J.S.K analyzed data, and J.S.K and M.B. wrote the paper; 
930 Competing interests: Authors declare no competing interests;

931 Data and materials availability: All data, code, and materials used in the analysis are available 932 in the repository: https://github.com/judyseinkim/Intuitive-Theories-of-Color and a detailed 933 description of analyses can be found in the following document: 934 https://rpubs.com/judyseinkim/color theory. 
950

951

952

953

954

955

956

957

958

959

960

961

962

963

964

965

966

967

968

969

970

971

972

\section{Supplementary Materials for}

Shared understanding of color among congenitally blind and sighted adults

Judy Sein Kim, Brianna Aheimer, Verónica Montané Manrara, Marina Bedny

This file includes:

Tables S1 to S4

Appendix

Correspondence to: judy.kim@yale.edu 


\begin{tabular}{lllll} 
Participant & Sex & Age & Highest education & Cause of blindness \\
\hline CB1 & F & 20 & HS & ROP \\
CB2 & F & 30 & 5 years BA & LCA \\
CB3 & F & 40 & some college & Microophthalmia \\
CB4 & M & 24 & HS & ROP \\
CB5 & M & 42 & BA & Bilateral anophthalmia \\
CB6 & F & 24 & MA & LCA \\
CB7 & M & 61 & MA & Congenital glaucoma \\
CB8 & F & 21 & some college & Fraser's syndrome, anophthalmia \\
CB9 & F & 34 & BA & ROP \\
CB10 & F & 25 & BA & Bilateral anophthalmia \\
CB11 & F & 20 & some college & LCA \\
CB12 & M & 40 & MA & LCA \\
CB13 & F & 18 & some HS & LCA \\
CB14 & F & 23 & BA & ROP \\
CB15 & F & 36 & BA & LCA \\
CB16 & M & 38 & BA & LCA \\
CB17 & F & 34 & MA & ROP \\
CB18 & F & 31 & HS & LCA \\
CB19 & F & 36 & BA, in med school & ROP \\
CB20 & M & 20 & some college & ROP
\end{tabular}

\begin{tabular}{llll} 
Average & & & \\
\hline Blind & $14 \mathrm{~F}$ & 30.85 & 15.43 years \\
& & $(\mathrm{SD}=10.59)$ & $(\mathrm{SD}=2.27)$ \\
Sighted & $14 \mathrm{~F}$ & $\begin{array}{l}31.21 \\
(\mathrm{SD}=11.21)\end{array}$ & $\begin{array}{l}15.79 \\
(\mathrm{SD}=1.82)\end{array}$
\end{tabular}

973

974

975

976

977

978

979

980

981

982

983

984

976

977

Table S1. Participant information. Sighted participants' demographics are only shown as averages.

$\mathrm{ROP}=$ retinopathy of prematurity, $\mathrm{LCA}=$ Leber's congenital amaurosis.

8

4




\begin{tabular}{ccc|cc} 
Experiment & Kind & Object & Rating & SD \\
\hline 1 & FC & go traffic & 6.4 & 1.57 \\
3 & FC & stop sign & 6.35 & 1.35 \\
1 & FC & street sign & 5.65 & 1.57 \\
1 & FC & fire truck & 5.55 & 1.57 \\
1 & FC & crayon & 5.5 & 2.09 \\
3 & FC & school bus & 5.3 & 1.89 \\
3 & FC & wedding dress & 5.25 & 1.71 \\
3 & FC & military uniform & 5.05 & 1.76 \\
3 & FC & recycling bin & 4.9 & 1.77 \\
3 & FC & paper & 4.75 & 2.36 \\
1 & FC & taxi cab & 4.55 & 1.82 \\
1 & FC & police uniform & 4.5 & 1.91 \\
1 & FC & dollar bill & 4.4 & 2.01 \\
1 & FC & basketball & 4.35 & 1.95 \\
3 & FC & pen & 4.35 & 2.11 \\
1 & FC & chalkboard & 4.2 & 2.17 \\
1 & FC & tennis ball & 4.05 & 2.04 \\
3 & FC & coin & 4.05 & 2.16 \\
1 & FC & lab coat & 4 & 2.10 \\
1 & NFC & toilet & 3 & 2.38 \\
1 & NFC & pants & 2.9 & 2.00 \\
1 & NFC & suitcase & 2.85 & 2.25 \\
1 & NFC & purse & 2.8 & 2.33 \\
1 & NFC & shoes & 2.75 & 1.86 \\
1 & NFC & couch & 2.5 & 2.06 \\
3 & NFC & mug & 2.5 & 2.19 \\
1 & NFC & towel & 2.4 & 2.01 \\
3 & NFC & fork & 2.3 & 2.15 \\
3 & NFC & laptop & 2.3 & 1.92 \\
3 & NFC & car & 2.25 & 1.71 \\
3 & NFC & cup & 2.2 & 1.96 \\
3 & NFC & soap & 2.2 & 1.88 \\
3 & NFC & table & 2.2 & 1.96 \\
1 & NFC & book & 2 & 1.97 \\
1 & NFC & lunch box & 1.9 & 1.45 \\
1 & NFC & vacuum & 1.7 & 1.38
\end{tabular}

986 Table S2. Function relevance judgments for real artifact color. Ratings obtained from MTurk 987 participants $(\mathrm{n}=20)$ for real artifacts, combined across Experiments 1 and 3. Participants were asked, "How 988 relevant is the color of a to its function?" and had to rate on a scale of 1 to 7 . FC: functional color,

989 NFC: non-functional color.

990 


\begin{tabular}{ccc|cc} 
Experiment & Kind & Object & Rating & SD \\
\hline 2 & FC & Arn (clear substance) & 4.84 & 1.75 \\
2 & FC & Bewt (coin) & 4.08 & 1.91 \\
2 & FC & Bollop (toxic waste container) & 5.04 & 1.88 \\
2 & FC & Toppee (road symbol) & 5.52 & 1.48 \\
2 & FC & Reeka (ceremonial jacket) & 5.52 & 2.09 \\
2 & NFC & Cano (sleep device) & 3.92 & 2.12 \\
2 & NFC & Maxus (thought recorder) & 3.24 & 1.9 \\
2 & NFC & Kanpa (odor sprayer) & 3.64 & 2.33 \\
2 & NFC & Flut (roof cleaner) & 3.56 & 1.98 \\
2 & NFC & Meepa (holographic device) & 3.32 & 2.04
\end{tabular}

993 Table S3. Function relevance judgments for novel artifact color. Ratings obtained from MTurk 994 participants $(\mathrm{n}=25)$ for novel artifacts, combined across Experiments 1 and 3. Participants were asked, 995 "How relevant is the color of a to its function?" and had to rate on a scale of 1 to 7 . FC: functional 996 color, NFC: non-functional color.

998 Explanations Key

\begin{tabular}{|c|c|}
\hline Just is & $\begin{array}{l}\text { "just is that way", "it's just nature/genetics/science", appealing to category (e.g., "it's a } \\
\text { type of vegetable/plant"), circular answers (e.g., for carrot: "it's a carrot") }\end{array}$ \\
\hline Process & "manufactured", "designed", "made", "painted", "grows", "photosynthesis" \\
\hline Depends on... & the part of object, what you use it for, temperature, weather, location, maturity \\
\hline Maker & manufacturer, God, "someone", brand, company \\
\hline Social & $\begin{array}{l}\text { "people like it that way", "that's what people want", individual preferences, "people want } \\
\text { variability/choice", aesthetics, "so people can use it for... (e.g., for pen "so people can } \\
\text { write with it") }\end{array}$ \\
\hline Material & $\begin{array}{l}\text { "made of... (e.g., metal, gold, porcelain)", "contains... (e.g., nutrient, chemical, } \\
\text { chlorophyll) }\end{array}$ \\
\hline Visibility & camouflage, "for contrast, to make it stand out", "to match other things" \\
\hline Convention & $\begin{array}{l}\text { tradition, "it's always been that way", government regulation, societal values (e.g., } \\
\text { patriarchy, purity), symbolism (e.g., cleanliness), for sake of uniformity or identification }\end{array}$ \\
\hline
\end{tabular}

1000 Table S4. A key of explanation types. Coders were trained on and used these guidelines when tagging

1001 explanations. 


\section{Appendix}

1004 In the Appendix, Experiment descriptions and instructions are listed in the order that they were administered to the participants (Experiment 2, Experiment 1, and Experiment 3). Trials within an experiment, however, are organized by condition, no in the order presented to participants.

\section{Instructions}

Imagine that you're an explorer, and on your travels, you've discovered an island in a remote corner of the world. This is your first day on the island. You learn that the people on this island call themselves Zorkas. They haven't made any contact with the outside world. The Zorka people appear to have a highly advanced culture. They have their own language, tools, machines, buildings, vehicles, foods, customs, and so on. The ecology on this island is also different from what we're used to: it has its own plant and animal life, unusual rocks, minerals, and so on. You're trying to learn about how things work on this island. During the course of the day, you encounter new animals, people, and objects. You observe their properties, and you need to make guesses about whether these properties apply to other animals, people, or objects of the same type. Each time we're going to ask you to take a guess based on seeing a single example of an object, animal or person. There are no correct answers to these questions, we just want to know your opinion.

[Bug example] Here's an example of a question we would ask during the task. Imagine that you come across an insect called a Blork on this island. This insect is skinny, bright orange, and has a big stinger. If you found another Blork on the island, how likely is it that it will also have a big stinger? Please rate the likelihood on a scale of 1 to 7 , where 1 means "unlikely" and 7 means "very likely". The rest of the number representing everything in between: 3 means "somewhat likely", 5 means "likely". To answer, you should try to use the entire range of the scale, meaning all the numbers between 1 and 7 , not just 1, 3, 5, 7 .

So what do you think? How likely is a Blork to have a big stinger on a scale from 1 to 7 ? [wait for answer]. [People example] Let's try another example. Say you observe a single Zorka person engaging in an unusual behavior. Before entering their house, they twirl around three times. If you saw a different Zorka person walking into their own house, how likely do you think it is that they will also do a twirl? Perhaps this is a Zorka custom, and that's what everyone on the island does. Alternatively, maybe this individual is just a whimsical person.

So what do you think? How likely are they to do a twirl? Again, rate on a scale of 1 to 7 , where 1 means "unlikely", and 3 means "somewhat likely", 5 means "likely" and 7 means "very likely". [wait for answer]. Great. We're done with the practice. Now we're going to move on to the real task. Do you have any questions before we start? Remember that there are no correct answers to these questions, we want to know your opinion, please give an answer for every trial.

\section{Color consistency (Natural kinds)}

[Natural Kinds Trial 1] You come across a Zorka man who is collecting some kind of liquid from a plant. The liquid is blue and frothy, and it lets out a hiss as it pours out. He lets you taste some of it, and it is sweet. He says that this liquid is called Atto. Zorka people like to drink Atto in the morning. How likely is it that the next time you come across more Atto, it is also blue? Rate on a scale of 1 to 7 , where 1 is 'unlikely', 3 is 'somewhat likely', 5 is 'likely, and 7 is 'very likely'. 
1047

1048

1049

1050

1051

1052

1053

1054

1055

1056

1057

1058

1059

1060

1061

1062

1063

1064

1065

1066

1067

1068

1069

1070

1071

1072

1073

1074

1075

1076

1077

1078

1079

1080

1081

1082

1083

1084

1085

1086

1087

1088

1089

1090

1091

1092

1093

1094

1095

1096

[Natural Kinds Trial 2] As you're walking around town, you notice a Zorka child who is eating an unfamiliar plant. It is round, orange, and crunchy in texture. He says that this plant is called an Onz. He says that he used to not like the Onz, but now it's his favorite thing to eat. How likely is it that the next time you come across another Onz, it is also orange? Rate on a scale of 1 to 7 , where 1 is 'unlikely', 3 is 'somewhat likely', 5 is 'likely, and 7 is 'very likely'.

[Natural Kinds Trial 3] As you're exploring a lake, you notice a Zorka scientist who is studying a dense, smooth, and yellow algae that is covering a rock. The scientist tells you that this algae is called Stime. She is trying to find an antidote, as Stime is slightly poisonous. How likely is it that the next time you come across more Stime, it is also yellow? Rate on a scale of 1 to 7 , where 1 is 'unlikely', 3 is 'somewhat likely', 5 is 'likely, and 7 is 'very likely'.

[Natural Kinds Trial 4] You tag alongside a group of Zorka miners into a cave. There you notice a miner excavating a green gem that is spiky and the size of a hand. It appears to be vibrating in place. The miners tell you that this gem is called an Enly, and that Enlies are used as an energy source by the Zorka people. How likely is it that the next time you come across another Enly, it is also green? Rate on a scale of 1 to 7 , where 1 is 'unlikely', 3 is 'somewhat likely', 5 is 'likely, and 7 is 'very likely'.

[Natural Kinds Trial 5] While taking a morning stroll, you come across a Zorka woman who is prying a strange fruit off a tree. The fruit is shaped like a fan, red, and has a hard skin. She tells you that this fruit is called a Blairo, and that she is making a Blairo pie to enter into a cooking competition. How likely is it that the next time you come across another Blairo, it is also red? Rate on a scale of 1 to 7 , where 1 is 'unlikely', 3 is 'somewhat likely', 5 is 'likely, and 7 is 'very likely'.

\section{Color consistency (Artifacts with non-functional color)}

[A-NFC Trial 1] A Zorka woman invites you into her home. There, you notice a gadget that is floating around the house, spraying an odorless chemical. The gadget is triangular, yellow, and the size of a thumb. She says that this gadet is called a Kanpa, and that her Kanpa is rather old. How likely is it that the next time you come across another Kanpa, it is also yellow? Rate on a scale of 1 to 7 , where 1 is 'unlikely', 3 is 'somewhat likely', 5 is 'likely, and 7 is 'very likely'.

[A-NFC Trial 2] You observe a Zorka man using a remote controller to operate an unfamiliar machine. The machine is very thin, covered in small dots, and green. It appears to be cleaning the roof of a house. He explains that this machine is called a Flut. Most Zorka families these days own a Flut. How likely is it that the next time you come across another Flut, it is also green? Rate on a scale of 1 to 7 , where 1 is 'unlikely', 3 is 'somewhat likely', 5 is 'likely, and 7 is 'very likely'.

[A-NFC Trial 3] You come across a Zorka teen who is speaking into a device which is orange, spherical, and smooth all around. There is a holographic image of a person coming out of the device. She says that this device is called a Meepa. and that she can't imagine living without her Meepa. How likely is it that the next time you come across another Meepa, it is also orange? Rate on a scale of 1 to 7 , where 1 is 'unlikely', 3 is 'somewhat likely', 5 is 'likely, and 7 is 'very likely'.

[A-NFC Trial 4] In a Zorka store window, you see a cube-shaped contraption on display. It is blue and the size of a human head. He tells you that this contraption is called a Cano. You can put it near your bed and night, and it helps you sleep. This Cano is the newest model. How likely is it that the next time you come across another Cano, it is also blue? Rate on a scale of 1 to 7 , where 1 is 'unlikely', 3 is 'somewhat likely', 5 is 'likely, and 7 is 'very likely'. 
1097

1098

1099

1100

1101

1102

1103

1104

1105

1106

1107

1108

1109

1110

1111

1112

1113

1114

1115

1116

1117

1118

1119

1120

1121

1122

1123

1124

1125

1126

1127

1128

1129

1130

1131

1132

1133

1134

1135

1136

1137

1138

1139

1140

1141

1142

1143

1144

[A-NFC Trial 5] While walking around the city, you come across a Zorka person holding an unusual device. The device is shaped like a bowl, rough in texture, and red. She tells you that this is device is called a Maxus, and that it was expensive to buy. The Maxus can record your thoughts, even if you don't speak them out loud. How likely is it that the next time you come across another Maxus, it is also red? Rate on a scale of 1 to 7, where 1 is 'unlikely', 3 is 'somewhat likely', 5 is 'likely, and 7 is 'very likely'.

\section{Color consistency (Artifacts with functional color)}

[A-FC Trial 1] You notice a Zorka teenager buying food with a square coin. She lets you examine it. It is very cold to the touch and red. She explains that this coin is called a Bewt, and that Bewt coins are the main currency used by the Zorka people. How likely is it that the next time you come across another Bewt, it is also red? Rate on a scale of 1 to 7 , where 1 is 'unlikely', 3 is 'somewhat likely', 5 is 'likely, and 7 is 'very likely'.

[A-FC Trial 2] You encounter some Zorka workers at a construction site. They are making the walls of a building using a clear, thick, and malleable substance. They tell you that this substance is called Arn. Arn walls are currently very trendy in Zorka houses. How likely is it that the next time you come across more Arn, it is also clear? Rate on a scale of 1 to 7 , where 1 is 'unlikely', 3 is 'somewhat likely', 5 is 'likely, and 7 is 'very likely'.

[A-FC Trial 3] You come across a Zorka government official who is examining a symbol in the middle of the road. It is hexagonal, green, and the size of a foot. He tells you that this symbol is called a Topee, and that it means 'look up!'. He is conducting a routine check-up to make sure it is still in place. How likely is it that the next time you come across another Topee, it is also green? Rate on a scale of 1 to 7 , where 1 is 'unlikely', 3 is 'somewhat likely', 5 is 'likely, and 7 is 'very likely'.

[A-FC Trial 4] While exploring the city, you notice a Zorka person dumping something into an oval container. The container is very big, orange, and appears to be emitting a low humming sound. He explains that this container is called a Bollop, and that by Zorka law, all toxic waste needs to be disposed in a Bollop. How likely is it that the next time you come across another Bollop, it is also orange? Rate on a scale of 1 to 7 , where 1 is 'unlikely', 3 is 'somewhat likely', 5 is 'likely, and 7 is 'very likely'.

[A-FC Trial 5] You observe a group of Zorka people all wearing sleek, tight-fitting blue jackets with on their way to some kind of event. One of the people tells you that they are on their way to a Reeka, which is a coming-of-age ceremony that is important in Zorka culture. How likely is it that the next time you come across another Zorka attending a Reeka, they are also wearing blue? Rate on a scale of 1 to 7 , where 1 is 'unlikely', 3 is 'somewhat likely', 5 is 'likely, and 7 is 'very likely'.

\section{Usage consistency (Natural kinds)}

[Natural Kinds Trial 1] You see an orange creature that is being chased by an elderly Zorka man across a field. The creature is hairless, has three tails, and makes a piercing sound as it runs. The elderly man stops to explain that this creature is called a Koshi. Koshi are native to this island. How likely is it that the next time you come across another Koshi, it is also being chased? Rate on a scale of 1 to 7 , where 1 is 'unlikely', 3 is 'somewhat likely', 5 is 'likely, and 7 is 'very likely'. 
1145

1146

1147

1148

1149

1150

1151

1152

1153

1154

1155

1156

1157

1158

1159

1160

1161

1162

1163

1164

1165

1166

1167

1168

1169

1170

1171

1172

1173

1174

1175

1176

1177

1178

1179

1180

1181

1182

1183

1184

1185

1186

1187

1188

1189

1190

1191

1192

1193

1194

[Natural Kinds Trial 2] You come across a Zorka farmer who is taking a nap on a gigantic boulder. It is yellow, flat, and appears to be hovering slightly off the ground. The farmer wakes up as you approach. The farmer tells you that this boulder is called a Poom, and that Pooms are famous for how large they can get. How likely is it that the next time you come across another Poom, it is also being slept on? Rate on a scale of 1 to 7 , where 1 is 'unlikely', 3 is 'somewhat likely', 5 is 'likely, and 7 is 'very likely'.

[Natural Kinds Trial 3] At the foot of a mountain, you observe a Zorka man picking up a stone from the ground. He throws it at the mountain. The stone is elongated, shimmery, and green. The man says that this stone is called a Borg, and that Borgs are everywhere. He likes to come here to clear his head sometimes. How likely is it that the next time you come across another Borg, it is also being thrown? Rate on a scale of 1 to 7, where 1 is 'unlikely', 3 is 'somewhat likely', 5 is 'likely, and 7 is 'very likely'.

[Natural Kinds Trial 4] While you are running home from the rain, you notice a strange flower. It is blue and has enormous square petals. A Zorka girl appears to be sitting under it. The girl explains that this plant is called a Norpee, and that her family grows a Norpee in their backyard, too. How likely is it that the next time you come across another Norpee, it is also being used to shield from rain? Rate on a scale of 1 to 7 , where 1 is 'unlikely', 3 is 'somewhat likely', 5 is 'likely, and 7 is 'very likely'.

[Natural Kinds Trial 5] You come across a young Zorka woman who is ripping out a strange plant from the ground. The plant is fuzzy, red, and has jagged leaves. The leaves flop around with the wind. She says that this plant is called an Irve. She tells you that the she likes the way Irves smell. How likely is it that the next time you come across another Irve, it is also being ripped out of the ground? Rate on a scale of 1 to 7 , where 1 is 'unlikely', 3 is 'somewhat likely', 5 is 'likely, and 7 is 'very likely'.

\section{Usage consistency (Artifacts)}

[Artifacts Trial 1] While exploring a Zorka factory, you find a Zorka worker operating a pointy, asymmetrical, and green machine. It shakes back and forth without making a sound, and appears to be making a square hole. He tell you that this machine is called a Xenop, and that he thinks that Xenops are rather ugly. How likely is it that the next time you come across another Xenop, it is also being used to make a square hole? Rate on a scale of 1 to 7 , where 1 is 'unlikely', 3 is 'somewhat likely', 5 is 'likely, and 7 is 'very likely'.

[Artifacts Trial 2] You're exploring an elderly Zorka woman's home, and you find an unfamiliar red contraption. It has circular compartments, reaches all the way up to the ceiling, and a variety of objects appear to be stored in it. The elderly woman tells you that this contraption is called a Trint. She doesn't know a Zorka who doesn't own a Trint. How likely is it that the next time you come across another Trint, it is also storing things? Rate on a scale of 1 to 7 , where 1 is 'unlikely', 3 is 'somewhat likely', 5 is 'likely, and 7 is 'very likely'.

[Artifacts Trial 3] You hear two Zorka children laughing, and go to investigate. You see that they are playing with a rectangular, blue, and sparkly toy. They keep passing it back and forth to each other. They tell you that this toy is called a Soof, and that they saved up for a long time to buy this Soof. How likely is it that the next time you come across another Soof, it is also being played with? Rate on a scale of 1 to 7 , where 1 is 'unlikely', 3 is 'somewhat likely', 5 is 'likely, and 7 is 'very likely'. 
1195

1196

1197

1198

1199

1200

1201

1202

1203

1204

1205

1206

1207

1208

1209

1210

1211

1212

1213

1214

1215

1216

1217

1218

1219

1220

1221

1222

1223

1224

1225

1226

1227

1228

1229

1230

1231

1232

1233

1234

1235

1236

1237

1238

1239

1240

1241

1242

1243

1244

[Artifacts Trial 4] You walk past a Zorka person who is blowing into a coily, bumpy, and yellow instrument. The instrument makes a haunting howling sound. She says that this instrument is called a Quag, and that Quags have been around for decades. How likely is it that the next time you come across another Quag, it is also being blown into? Rate on a scale of 1 to 7 , where 1 is 'unlikely', 3 is 'somewhat likely', 5 is 'likely, and 7 is 'very likely'.

[Artifacts Trial 5] You come across a Zorka person using a loud, orange, and bulky machine. Large rocks go in from one end and a gooey liquid comes out of the other. He explains that this machine is called an Olan. The Olan was invented by a Zorka person from his town. How likely is it that the next time you come across another Olan, it is also being used to make a gooey liquid? Rate on a scale of 1 to 7 , where 1 is 'unlikely', 3 is 'somewhat likely', 5 is 'likely, and 7 is 'very likely'.

\section{Fillers (Natural kinds)}

[Natural Kinds Trial 1] You notice a Zorka person jogging around the lake. He makes a wide arc around a strange fruit that is lying on the ground. The fruit is long, coiled up, and has square leaves. The person says that this fruit is called a Yobal, and that you never want to step on a Yobal. How likely is it that the next time you come across another Yobal, it also has square leaves? Rate on a scale of 1 to 7 , where 1 is 'unlikely', 3 is 'somewhat likely', 5 is 'likely, and 7 is 'very likely'.

[Natural Kinds Trial 2] You see a strange creature that is perched on the roof of a Zorka house. The creature is very fluffy and has four wings. A Zorka police officer starts shouting at it to get off the roof. The police officer says that this creature is called a Walla, and that Wallas often steal people's things. How likely is it that the next time you come across another Walla, it also has four wings? Rate on a scale of 1 to 7 , where 1 is 'unlikely', 3 is 'somewhat likely', 5 is 'likely, and 7 is 'very likely'.

[Natural Kinds Trial 3] Inside a Zorka house, you find a rock that is being used as a paperweight. It is speckled, heavy for its size, and has lumps all over it. The Zorka homeowner tells you that this rock is called a Chom. She found this Chom while on holiday last year. How likely is it that the next time you come across another Chom, it also has lumps all over it? Rate on a scale of 1 to 7 , where 1 is 'unlikely', 3 is 'somewhat likely', 5 is 'likely, and 7 is 'very likely'.

[Natural Kinds Trial 4] While following a small stream, you find a strange creature that is resting on the ground. It is scaly, large, and snoring very loudly. A Zorka passerby tells you that this creature is called a Hyto, and that Hytos are very friendly, so you can pet them if you want. How likely is it that the next time you come across another Hyto, it is also snoring very loudly? Rate on a scale of 1 to 7 , where 1 is 'unlikely', 3 is 'somewhat likely', 5 is 'likely, and 7 is 'very likely'.

[Natural Kinds Trial 5] You're walking around a field at night, and you find a plant that is glowing in the dark. It is covered in tiny thorns and has sharp leaves. You pick it off the stem and count eight thorns. A Zorka person tells you that this plant is called a Drapa, and that Drapa symbolize strength in Zorka culture. How likely is it that the next time you come across another Drapa, it also has exactly eight thorns? Rate on a scale of 1 to 7 , where 1 is 'unlikely', 3 is 'somewhat likely', 5 is 'likely, and 7 is 'very likely'.

[Natural Kinds Trial 6] You come across a Zorka woman who is wearing a necklace that has a type of gem that you've never seen before. The gem is shaped like a teardrop and looks very fragile. The woman explains that this gem is called an Uzoo, and that she inherited this Uzoo from her late grandmother. How likely is it that the next time you come across another Uzoo, it is 
shaped like a teardrop? Rate on a scale of 1 to 7 , where 1 is 'unlikely', 3 is 'somewhat likely', 5 is 'likely, and 7 is 'very likey'.

[Natural Kinds Trial 7] You come across a Zorka boy who is leaning over a dainty plant, smelling it. The plant comes up to your knees and has many long tentacles. He tells you that this plant is called Jox. The smell of the Jox can predict the weather. How likely is it that the next time you come across another Jox, it also comes up to your knees? Rate on a scale of 1 to 7 , where 1 is 'unlikely', 3 is 'somewhat likely', 5 is 'likely, and 7 is 'very likely'.

\section{Fillers (Artifacts)}

[Artifacts Trial 1] You're walking around a residential neightborhood, and you come across an elderly Zorka man who is rubbing his hand over a strange contraption. It looks like a rounded square and is attached to the wall of a house. The elderly man explains that this contraption is called a Gep. Gep can warm your hands when it's cold outside. How likely is it that the next time you come across another Gep, it is also a rounded square? Rate on a scale of 1 to 7 , where 1 is 'unlikely', 3 is 'somewhat likely', 5 is 'likely, and 7 is 'very likely'.

[Artifacts Trial 2] You spot a group of Zorka teenagers who are sitting around an unfamiliar object. It looks like three balls stacked on top of each other, and it seems to be emitting sparks. The teenagers explain that this is object is called a Desh. It is the newest Zorka game device. The rules of the game is different each time you turn the Desh on. How likely is it that the next time you come across another Desh, it is also emitting sparks? Rate on a scale of 1 to 7 , where 1 is 'unlikely', 3 is 'somewhat likely', 5 is 'likely, and 7 is 'very likely'.

[Artifacts Trial 3] A Zorka man invites you into his house and shows you a large indoor pool filled with cold liquid. He says that the liquid in this pool can heal minor wounds if you sit in it for a long time. He says that this type of pool is called a Nox, and brags that not everyone can afford to have a Nox in their house. How likely is it that the next time you come across another Nox, it is also large? Rate on a scale of 1 to 7 , where 1 is 'unlikely', 3 is 'somewhat likely', 5 is 'likely, and 7 is 'very likely'.

\section{Experiment 1 (Real objects)}

\section{Instructions}

Let's move on to the next task. This time, I'm going to ask you very similar types of questions as before. But these questions will be about objects that you're familiar with in the real world, so you're no longer thinking about the imaginary island.

[Texture example] Again, some of the answers to the following questions will feel obvious and others less so. For example, we might ask you: what is one possible texture of sand paper? Here, most people will say "rough". For each object, we will then ask you to rate, on a scale of 1 to 7, how likely it is that two randomly chosen examples of the object are likely to have the same property. So for sand paper, we would ask you tell us how likely it is that two randomly chosen pieces of sand paper would have the same texture. The scale is the same as before, where 1 means "unlikely", and 3 means "somewhat likely", 5 means "likely" and 7 means "very likely". What do you think? How likely are two random pieces of sand paper to have the same texture? [wait for answer].

[Personality example] Let me give you another example. When we ask people to tell us the personality type that a cat might have, some people would say "loner." We would then ask, if you picked two random cats, how likely are they to have the same personality? You might think, 
most cats are loners, so two random cats are pretty likely to have the same personality. But you might also think, not all cats are like that: sometimes cats can be very friendly and outgoing.

So what do you think? Can you rate how likely it is that two random cats will have the same personality, on a scale of 1 to 7 where 1 means "unlikely" and 7 means "very likely"? [wait for answer].

As before, remember to use the entire range of the scale, meaning all the numbers between 1 and 7 . And remember that there are no correct answers to these questions, we just want to know your opinion. Do you have any questions? Great, now we're going to start the real task."

\section{Color consistency}

What is one common color of ? If you picked two (pieces of) $s$ at random, how likely are they to be the same color? Rate on a scale of 1 to 7, where 1 means "unlikely", 3 means "somewhat likely", 5 means "likely", and 7 means "very likely".

\section{Natural kinds}

strawberry, banana, broccoli, lemon, coal, snow, flamingo, elephant, ruby, pearl

Artifacts with non-function-relevant color

pants, mug, book, purse, crayon, toilet, lunch box, suitcase, couch, shoes, vacuum

Artifacts with function-relevant color

"go" traffic light, fire truck, basketball, taxi cab, police uniform, dollar bill, tennis ball, chalkboard, street sign

\section{Usage consistency}

What is one common thing you can do with a ? If you picked two people at random and asked them each to do something with a , how likely are they to do the same thing? Rate on a scale of 1 to 7, where 1 means "unlikely", 3 means "somewhat likely", 5 means "likely", and 7 means "very likely".

\section{Natural kinds}

wood, rock, mud, gold, grass, leaf, tree bark, dirt, flower

\section{Artifacts}

hole puncher, stapler, hammer, drill, iron, toaster, coffee maker, bed, pencil, bathtub

\section{Fillers}

What is one common size of dogs? If you picked two dogs at random, how likely are they to be the same size?

What is one common size of pumpkins? If you picked two pumpkins at random, how likely are they to be the same size?

What is one common length of cucumbers? If you picked two cucumbers at random, how likely are they to be the same length? 
1341

1342

1343

1344

1345

1346

1347

1348

1349

1350

1351

1352

1353

1354

1355

1356

1357

1358

1359

1360

1361

1362

1363

1364

1365

1366

1367

1368

1369

1370

1371

1372

1373

1374

1375

1376

1377

1378

1379

1380

1381

1382

1383

1384

1385

1386

1387

1388

1389

What is one common length of tree branches? If you picked two tree branches at random, how likely are they to be the same length?

What is one common shape of pebbles? If you picked two pebbles at random, how likely are they to be the same shape?

What is one common shape of seashells? If you picked two seashells at random, how likely are they to be the same shape?

What is one common texture of oranges? If you picked two oranges at random, how likely are they to be the same texture?

What is one common texture of sand? If you picked two handfuls of sand at random, how likely are they to be the same texture?

What is one common size of watermelons? If you picked two watermelons at random, how likely are they to be the same size?

What is one common shape of mice? If you picked two mice at random, how likely are they to be the same shape?

What is one common texture of acorns? If you picked two acorns at random, how likely are they to be the same texture?

What is one common shape of snakes? If you picked two snakes at random, how likely are they to be the same shape?

What is one common texture of pineapples? If you picked two pineapples at random, how likely are they to be the same texture?

What is one common height of chairs? If you picked two chairs at random, how likely are they to be the same height?

What is one common shape of coffee tables? If you picked two coffee tables at random, how likely are they to be the same shape?

What is one common length of knives? If you picked two knives at random, how likely are they to be the same length?

What is one common texture of rugs? If you picked two rugs at random, how likely are they to be the same texture?

What is one common texture of coats? If you picked two coats at random, how likely are they to be the same texture?

What is one common size of bowls? If you picked two bowls at random, how likely are they to be the same size?

What is one common texture of doors? If you picked two doors at random, how likely are they to be the same texture? 
1391

1392

1393

1394

1395

1396

1397

1398

1399

1400

1401

1402

1403

1404

1405

1406

1407

1408

1409

1410

1411

1412

1413

1414

1415

1416

1417

1418

1419

1420

1421

1422

1423

1424

1425

1426

1427

1428

1429

1430

1431

1432

\section{Instructions}

For this next task, we're going to ask you some more detailed questions about objects in the real world. This time, there will be a series of questions for each object.

[Q1 - most common color] First, we're going to start by asking you something like, "What is the most common texture of pies?" Notice that this question is slightly different from before, when we asked, "What is a common texture of pies?

[Q2 - variance across instances] Let's say that you answered, "The most common texture of pies is "crumbly'." Next, we will ask, "Are all pies crumbly, yes or no?" If you answer "No," then we will ask you to list all the other textures of pies. So for example, here you might say pies, are also "creamy", "smooth", "flaky", and "chunky".

The next question, then, is the same as what we asked in the last task: "If you picked two pies at random, how likely are they to have the same texture? Rate on a scale of 1 to 7 , where 1 means "unlikely", 3 means "somewhat likely", 5 means "likely", and 7 means "very likely". So, what would you say? How likely are two randomly chosen pies to have the same texture?

[Q3 - variance within object] Great. Next, we're going to ask you, "Are all parts of a pie a single texture, or does texture vary across the pie?" Say you answered, "The texture varies across the pie". We would then ask you to describe how the texture varies. You might say, a pie can be smooth or creamy on the inside, but it has a crumbly crust at the bottom.

[Q4 - explanation] Next, we will ask, "Why do pies have that texture?" This question is meant to be very open-ended, so you should provide whatever explanation seems right to you. If you had answered that "All pies are crumbly," then you should provide an explanation for why all pies are crumbly. If you had answered that "No, not all pies are crumbly, some are smooth, flaky, and so on", then you should provide an answer for why pies are all of those different textures. Does that make sense?

[Q5 - confidence rating] Finally, we're going to ask how confident you are about the answers you provided about that object, again by rating on a scale of 1 to 7 . This time, 1 means "not confident", and 7 means "very confident". So for the numbers in between: 3 would be "somewhat confident", and 5 would be "confident". So, on a scale of 1 to 7 , how confident are you of your knowledge about the texture of pies?

\section{Experimental trials \\ Natural kinds \\ apple, blueberry, carrot, corn, fire, kiwi, polar bear, spinach}

Artifacts with non-function-relevant color

car, cup, fork, laptop, pen, soap, table, towel

Artifacts with function-relevant color

coin, lab coat, military uniform, paper, recycling bin, school bus, stop sign, wedding dress 